\title{
A review on initiatives for the management of daily medical emergencies prior to the arrival of emergency medical services
}

\author{
Niki Matinrad ${ }^{1}$ (D) Melanie Reuter-Oppermann ${ }^{2}$ (D)
}

Accepted: 28 July 2021 / Published online: 18 September 2021

(c) The Author(s) 2021

\begin{abstract}
Emergency services worldwide face increasing cost pressure that potentially limits their existing resources. In many countries, emergency services also face the issues of staff shortage-creating extra challenges and constraints, especially during crisis times such as the COVID-19 pandemic-as well as long distances to sparsely populated areas resulting in longer response times. To overcome these issues and potentially reduce consequences of daily (medical) emergencies, several countries, such as Sweden, Germany, and the Netherlands, have started initiatives using new types of human resources as well as equipment, which have not been part of the existing emergency systems before. These resources are employed in response to medical emergency cases if they can arrive earlier than emergency medical services (EMS). A good number of studies have investigated the use of these new types of resources in EMS systems, from medical, technical, and logistical perspectives as their study domains. Several review papers in the literature exist that focus on one or several of these new types of resources. However, to the best of our knowledge, no review paper that comprehensively considers all new types of resources in emergency medical response systems exists. We try to fill this gap by presenting a broad literature review of the studies focused on the different new types of resources, which are used prior to the arrival of EMS. Our objective is to present an application-based and methodological overview of these papers, to provide insights to this important field and to bring it to the attention of researchers as well as emergency managers and administrators.
\end{abstract}

$凶 \quad$ Niki Matinrad

niki.matinrad@liu.se

Melanie Reuter-Oppermann

oppermann@is.tu-darmstadt.de

1 Department of Science and Technology, Linköping University, Norrköping 60174, Sweden

2 Information Systems - Software and Digital Business Group, Technical University of Darmstadt, 64289 Darmstadt, Germany 
Keywords Emergency medical services (EMS) · First responders · Volunteers · Community first responders (CFR) - Automated external defibrillators (AEDs) . Drones

\section{Introduction}

Daily or everyday emergencies are frequent events with low magnitude of consequences (Quarantelli 1995). These emergencies can roughly be categorized into two groups of urgent and non-urgent. Within medical emergencies, urgent cases are lifethreatening, and in case of a life-threatening emergency, such as an out-of-hospital cardiac arrest (OHCA) or a stroke, every second matters. While in case of a stroke a patient needs to be taken to the hospital as soon as possible to have a higher chance of survival, an immediate treatment at the scene is crucial for OHCA patients (Herlitz et al. 2005, 2003; Fothergill et al. 2013). Many countries have well-established and wellequipped emergency medical services (EMS) systems that send trained paramedics or emergency medical assistants to the scene of emergencies. However, almost all EMS systems worldwide face an increasing cost pressure, often accompanied by a shortage of staff and other necessary resources, as well as the issue of long distances to sparsely populated areas (Weinholt 2015; Yousefi Mojir and Pilemalm 2016). In many countries, the COVID-19 pandemic has exacerbated staff shortage and shown the importance of using all available resources as efficiently as possible. This means that adequate response times for all patients, $24 / 7$, and throughout all regions during both normal and crisis times are difficult or even impossible to ensure.

Many planning alternatives for regular EMS exist that aim at minimizing response times while balancing the necessary and available resources. An overview on EMS logistics summarizing the planning problems and existing approaches as well as a description of a typical EMS system can be found in Reuter-Oppermann et al. (2017) or Bélanger et al. (2019), for example. Alternatively, to overcome the issues faced by the EMS and potentially reduce consequences of daily medical emergencies, several countries, including Sweden, Germany, the UK, and the Netherlands, have started initiatives utilizing new types of resources, human resources as well as equipment. Many initiatives send first responders or volunteers to the scene of emergencies to help patients before the EMS arrives. Others utilize automated external defibrillators (AEDs) that are located in public buildings or drones that can bring necessary resources to an emergency scene. These human resources and equipment form services that we call "pre-EMS services" in this study, because their utilization prior to the arrival of EMS can potentially contribute to saving lives of patients. Therefore, they can be described as services that help patients until the EMS arrives at the scene. While these services might help improve the response times, for example, they do not replace the regular system.

In this paper, we present a review of studies focused on pre-EMS services with the aim to provide insights to this field for both academics and practitioners. Even though the research field on pre-EMS services is relatively new, a good number of works exists that have studied the use of these new types of resources in medical emergency systems, from different perspectives including medical, technical, and logistical. 
In this study, we focus on pre-EMS services and distinguish two main categories for them, (1) human resources (e.g., first responders and volunteers) and (2) equipment (i.e., AEDs and drones). With the aim to present a comprehensive overview on exiting literature related to pre-EMS services, we investigate the use of these services for the management of daily medical emergencies. These services can be used in response to bigger emergencies such as disasters as well. However, as the scope of this paper is daily medical emergencies, we exclude other types of events such as disasters or mass casualty incidents.

To the best of our knowledge, this is the first review targeting pre-EMS services. Rather than analyzing individual papers and their contributions to the field, we aim to give an application-based and methodological overview of these papers, to provide insights to this field and to bring it to the attention of researchers as well as emergency managers and administrators. We consider papers that cover both quantitative and qualitative methods from all operations research / operations management (OM) and medical journals and conference proceedings.

The remainder of the paper is structured as follows. First, we define our selection and classification scheme in Sect. 2 and describe the literature on pre-EMS services in Sect. 3. Then, in Sect. 4, we present an overview of the existing pre-EMS services in those countries that were named in the reviewed papers and it was stated that their initiatives are now operational. Based on the presented overview on human resources and on equipment in Sect. 3, we first present some insights for managers in Sect. 5 and then formulate directions for future studies in Sect. 6 . We close the paper with a summary and conclusion in Sect. 7.

\section{Selection and classification scheme}

The earliest published study within daily medical emergencies focused on one of the new types of resources that we found was from 1982. We limited the time period of our literature review to the end of 2020. We used Scopus as the main search engine and Google Scholar as the complementary one, and included publications from all journals and conference proceedings. We used "emergency medical services" in combination with each of the following words separately to find relevant papers: "first responders", "automated external defibrillator", "drone", "unmanned aerial vehicle", and "volunteer". In addition, "stop the bleed" was searched individually. After several iterations of selection from all search results, which was initially 2127 papers that included duplicates as well, we selected 258 research papers that are included in this review. Besides duplicates, we excluded papers focusing on non-medical daily emergencies and disasters and on the application of the new types of resources outside of daily medical emergency context (e.g., physicians volunteering for studies conducted in a hospital). We also excluded papers that studied well-being (e.g., mental health) of new types of human resources or technological aspects of equipment (e.g., the technical design of drones or AEDs) as well as papers in which the focus was on EMS rather than pre-EMS services. On the medical side, we excluded papers focused on medical outcomes without any particular emphasize on pre-EMS services and their application within the studied medical emergency. 
The included studies have used both qualitative and quantitative methods to investigate different problems such as cost-effectiveness of pre-EMS services, their deployment and task assignment, and location planning / placement of equipment. We included studies with a medical perspective in this review as well because we believe that it is insufficient for a comprehensive review to consider only operations research (OR) literature. Health services research, for example, investigates the impact of different care options. The results of these studies can be used as a basis and motivation for OR models that for instance aim to improve the access by locating care sites. In addition, medical studies already had a significant impact on OR models in the past. An example is the introduction of survival probabilities in ambulance location models. Our investigations showed that the majority of studies focused on human resources are conducted within the medical area. Overall, the medical studies included in this review mostly focus on ways of and benefits of incorporating equipment and human resources into the EMS systems, such as survival rates of patients or response times. Studies focusing on technical and logistical perspectives investigate questions such as the deployment of resources and the placement of equipment.

Based on the selected papers that are reviewed in this study, we identified four main categories, namely type of emergency, type of data, methodology, and pre-EMS services. The majority of researchers tend to focus on one type of emergency and pre-EMS services. Therefore, these two categories are important parameters that can describe an emergency scenario. Type of data and methodology are aspects that researchers consider once they have defined a problem, showing the solution scenario. They choose relevant methods to gather data and to perform required analysis, examining their hypothesis or testing their developed model. Therefore, we found these four categories as the most relevant aspects in providing insight into the pre-EMS services literature. We describe type of emergency, type of data, and methodology in this section and detail pre-EMS services in Sect. 3.

\subsection{Type of emergency}

The majority of studies have considered one specific type of medical emergency. However, some works did not indicate a specific type of emergency or only excluded a specific type. Main recognized types of medical emergencies in the reviewed papers include OHCA, trauma, drowning, and bleeding. Emergencies of type trauma contain road traffic injuries as well. Papers that focus on bleeding are mostly concerned with the "stop the bleed" campaign and related studies. Consequently, we consider a total of five categories for emergency types: bleeding, drowning, general, OHCA, and trauma.

\subsection{Type of data}

To investigate an identified problem, researchers usually need data to test and verify their hypotheses or models. We found that authors of the reviewed papers have used one of the two data types: real data and hypothetical data. We grouped data gathered through field studies, such as questionnaires and observations, studies of archival records, or studies of an actual emergency under real data. Hypothetical data is when 
researchers use some reasonable numbers due to many reasons, such as lack of archival data.

\subsection{Methodology}

In the reviewed papers, researchers have used one or several qualitative or quantitative methods to investigate their intended problem. Within studies using quantitative methods, we found the following methods: cost-effectiveness analysis, mathematical programming, simulation, and statistical analysis. We found the following qualitative methods in the reviewed studies: focus group; interview; meta-analysis; pretest-posttest study (e.g., pretest-posttest cross-sectional design); prospective studies; real-life experiments including randomized trial, non-randomized trial, in-practice simulation, and training courses; retrospective studies; survey; and thematic analysis. For those works with more than one method (e.g., a retrospective study has been followed by a statistical analysis), we have categorized the work based on the method we considered the main one.

\section{Pre-EMS services}

Tasked with providing timely pre-hospital medical care and saving lives of patients outside of hospitals, EMS are important actors in the healthcare system (Pozner et al. 2004; Ingolfsson 2013). In the majority of cases, ambulances with paramedics, emergency medical technicians or assistants, or registered nurses are dispatched to patients. After an initial treatment, if necessary, they can potentially take patients to hospitals and medical centers. In order to fulfil response time thresholds with a reasonable number of resources, ambulances must be placed efficiently. In EMS logistics, locating ambulances and ambulance bases is probably the most important planning problem, at least the one that has been studied the most. While in general the aim is to reach patients as fast as possible in case of an emergency, different objectives are used in ambulance location problems, such as maximizing coverage, minimizing response times, and maximizing survival probabilities. Further information about EMS logistics and planning problems can be found in Aringhieri et al. (2017), Reuter-Oppermann et al. (2017) and Bélanger et al. (2019), for example.

Already for some time, EMS providers worldwide have been facing two major challenges that lead to resource shortage problems: (1) budget cutbacks and (2) centralization of resources leading to longer response times to sparsely populated areas (Matinrad 2019). Additionally, in some countries fewer people are willing to work as professionals in EMS, and therefore, a shortage of human resources exists as well (DRK-Landesverband Baden-Württemberg e.V. and DRK-Landesverband Badisches Rotes Kreuz e.V 2018; Uppal and Gondi 2019). Thus, pre-EMS services have been introduced in the pre-hospital healthcare system and are utilized more frequently. In general, pre-EMS services, including human resources and equipment, have been facing rising attention during recent years especially since 2010 (see Fig. 3). These 


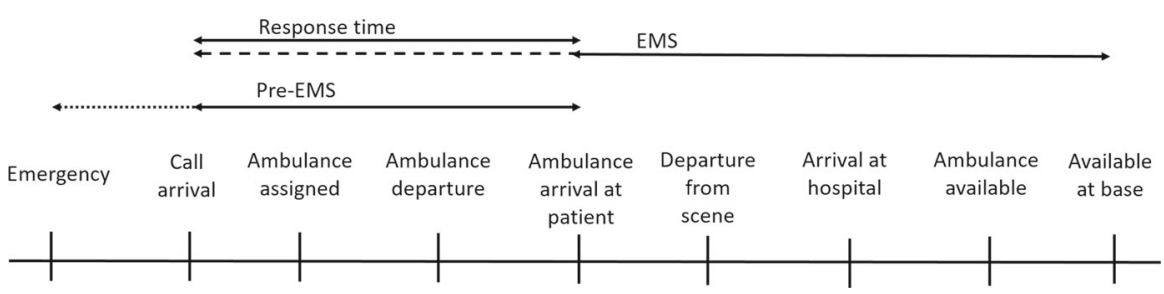

Fig. 1 Pre-EMS services in the emergency response process

services have not traditionally been part of emergency response systems and nowadays are used prior to the arrival of an (EMS) ambulance.

The classical emergency response process starts with the call arrival (e.g., ReuterOppermann et al. (2017); Aringhieri et al. (2017)). As shown in Fig. 1, pre-EMS services might be provided at the scene of an emergency during the EMS response time, until an ambulance arrives. In case of bystanders at the scene, pre-EMS services might even start before the call takes place. If resources like volunteers or drones are assigned by the coordination center, it is only valuable if they arrive (significantly) before the ambulance.

In Fig. 2 we show human resources (i.e., actors) and equipment contributing to emergency management. The center of this figure displays the emergency management life cycle, which is seen widely in disaster management literature (e.g., Coppola (2006); Nikbakhsh and Farahani (2011)). This cycle is, however, applicable to the management of daily emergencies as well (Matinrad 2019). As this figure shows, the emergency management life cycle consists of four phases of mitigation, preparedness, response, and recovery. While professional emergency management actors (i.e., ambulances, call centers, fire and rescue services (FRS), and police) are involved in all four phases to a greater or lesser extend, new types of actors (i.e., community first responders, laypersons and bystanders, semi-professionals, and volunteers) are mostly involved in the response phase. These human resources need some equipment in their response operations. The equipment used for medical emergencies, classified into two categories of medical equipment (i.e., first-aid kits and AEDs) and transport equipment (i.e., drones and vehicles), are also presented in this figure. These equipment are involved in both phases of preparedness and response. It should be noted that medical equipment in this figure are only those used by the new types of actors. The arrows coming from outside of emergency management life cycle boundary connects each of the resource categories to the phase(s) they are involved in.

Based on the resource type that researchers have focused on, we grouped studies on pre-EMS services into two main categories of human resources and equipment. We used the three-year moving average for both categories to inspect the rate of growth of pre-EMS services literature and present the results in Fig. 3. As can be seen in this figure, both human resources and equipment have incremental trends with a continuously positive rate of growth since 2014. These trends clearly show a growing interest in pre-EMS services especially in the recent years.

In the remainder of this section, we will provide an overview of studies on human resources and equipment that are used in pre-EMS services in Sects. 3.1 and 3.2, 


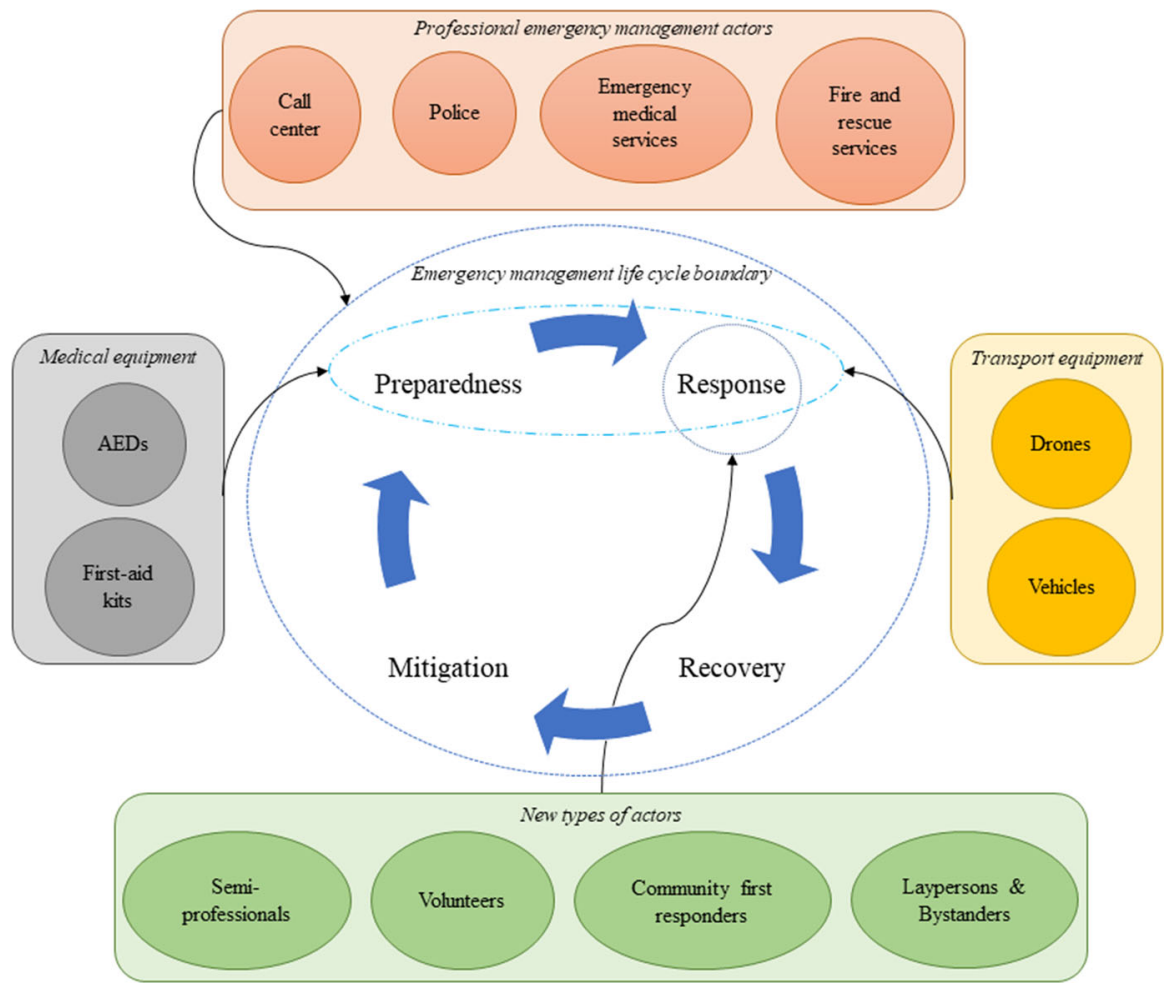

Fig. 2 Actors and equipment involved in emergency management life cycle

respectively. Then, in Sect. 3.3 we will further analyze publications that have used mathematical programming as their main methodology.

\subsection{Human resources}

We categorize human resources that are used in pre-EMS services into four main groups:

- Community first responders (CFR)

- First responders

- Laypersons and bystanders

- Volunteers.

The subcategory $C F R$ includes people who are not part of the professional emergency management system, but know how to handle (some, if not all) medical emergencies, because they either have received basic medical training (e.g., school nurses) or they are medically educated such as nurses and doctors. In some literature and initiatives this category might be also known as semi-professionals (e.g., Granberg et al. 2016, 2017; Yousefi Mojir and Pilemalm 2013). First responders include FRS and police. These organizations are already active in professional emergency manage- 


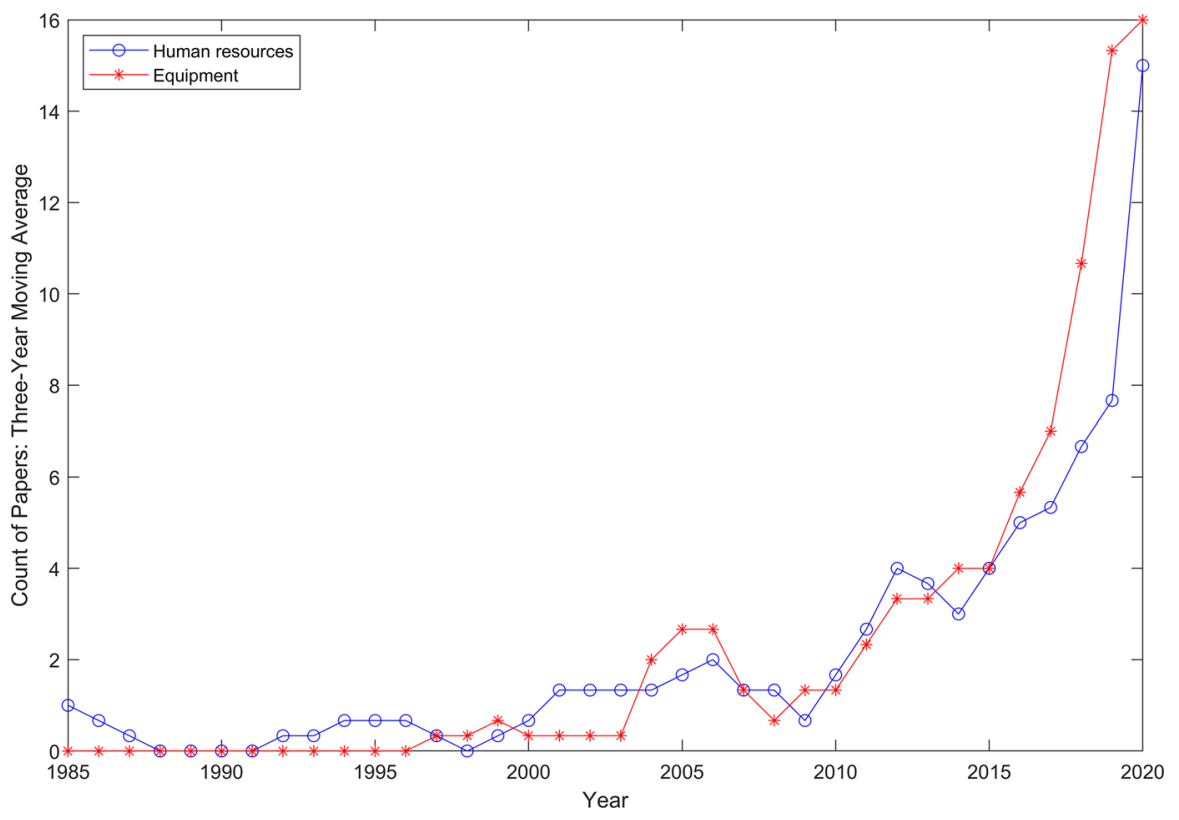

Fig. 3 Three-year moving average of number of papers published in all journals and conference proceedings

ment systems but are included in this list, because their primary roles are non-medical. In this context, FRS and police respond to some medical emergencies and provide help to patients prior to the arrival of EMS. According to the Merriam-Webster dictionary, laypersons are those people who "do not belong to a specif profession or are not expert in some fields". Therefore, in the context of pre-EMS services, laypersons are neither affiliated with EMS nor have any formal medical training. According to Nord (2017), bystanders can include both laypersons or medically educated people (e.g., off-duty healthcare personnel). Volunteers are people who volunteer to help in case of emergencies and depending on their integration within the emergency response systems, they might be well trained, equipped, and experienced (e.g., firefighter volunteers) or just have some minimum level of training (Matinrad 2019). In the literature, we found that some researchers use these terms interchangeably. For instance, they have used laypersons while they are actually referring to volunteers. Therefore, we categorized the 127 human resources papers here based on the actual subcategory that researchers have referred to rather than solely relying on the term they have used in their studies.

In the remaining part of this section, we first present general attributes of human resources within pre-EMS services in Sect. 3.1.1. Then, in Sect. 3.1.2 we provide cross tabulations of four main categories of these resources outlined in Sects. 2 and 3.1.

\subsubsection{General attributes}

In Table 1 we list the number of papers per year for each subcategory of human resources. As it can be seen from this table, most papers in human resources are 
published after 2000 with the highest number published in 2020. Laypersons and bystanders have the highest number of publications (44), followed by first responders (40) and volunteers (37). CFR with six papers has the lowest number of publications within human resources. The reason for the few publications focusing on CFR might be because this group can also be considered under the subcategory volunteers.

Within each subcategory, researchers have focused on a group of actors that are relevant to that subcategory and we call them "focus group" in this study. In Table 2 we present the number of papers relevant to each subcategory and focus group. In this table, medical staff includes general practitioners, general surgery residents, surgical trainees, medical students and research trainees, and off-duty EMS personnel. The focus group multiple actors consists of FRS and police officers that can be accompanied by one or several other actors including private security personnel, volunteers, and bystanders. Volunteers as well as laypersons and bystanders have civilians as their main focus group. The classification of the reviewed works in this table is dependent on the aim and structure of the studies, besides the relation between the subcategory and the focus group. Some additional observations regarding these classifications include the following.

- Even though medical staff is generally a focus group related to CFR, sometimes it relates to a different subcategory based on the aim of the study. In one study surgical trainees were used to simulate a tourniquet application in order to examine tourniquet instructions that will be used by laypersons and bystanders. In another study off-duty EMS personnel have acted as volunteers to investigate a volunteer response program. While the subcategory of the former study is laypersons and bystanders and that of the latter is volunteers, both studies have medical staff as their focus group.

- FRS is a focus group generally associated with the subcategory first responders. However, in a study researchers have investigated the development of a mobilevolunteer program and used off-duty FRS as volunteers in the trial. Consequently, even though the focus group of this study is categorized under FRS, because the aim of the investigation was related to volunteers, its subcategory is volunteers.

- Usually the subcategory CFR is associated with one of focus groups that are not affiliated with EMS but have some level of medical training (e.g., school nurses). However, in one study, in order to investigate the possibility of introduction and implementation of a CFR system, researchers have sent out a survey to 1350 residents. Therefore, as the aim of the study concerns CFR, the study is categorized as $C F R$, but the focus group is civilians.

In Table 3 we provide a closer look at the number of published papers based on each type of emergency in each of the continents. As can be seen from this table, 51 papers $(40 \%)$ are conducted within Europe. From these publications, 15 studies are related to Sweden, six to the Netherlands and six to the UK. European researchers have focused mostly on OHCA, while those in North America have studied bleeding and OHCA almost equally. The studies on bleeding in North America are a result of the "Stop the Bleed" campaign that was initiated after a number of mass casualty incidents in the USA. North America has the second highest number of studies, 45 papers (35\%), with 38 studies related to the USA. 16 papers (13\%) are related to Asia 


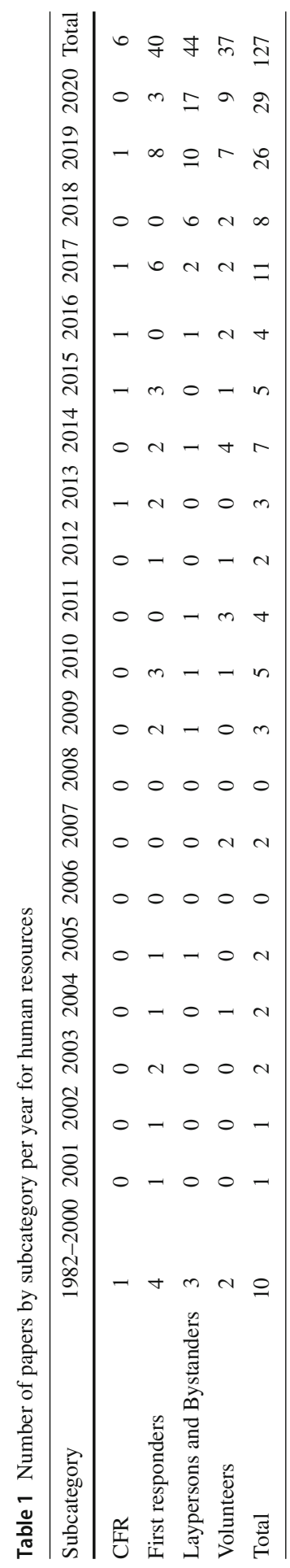




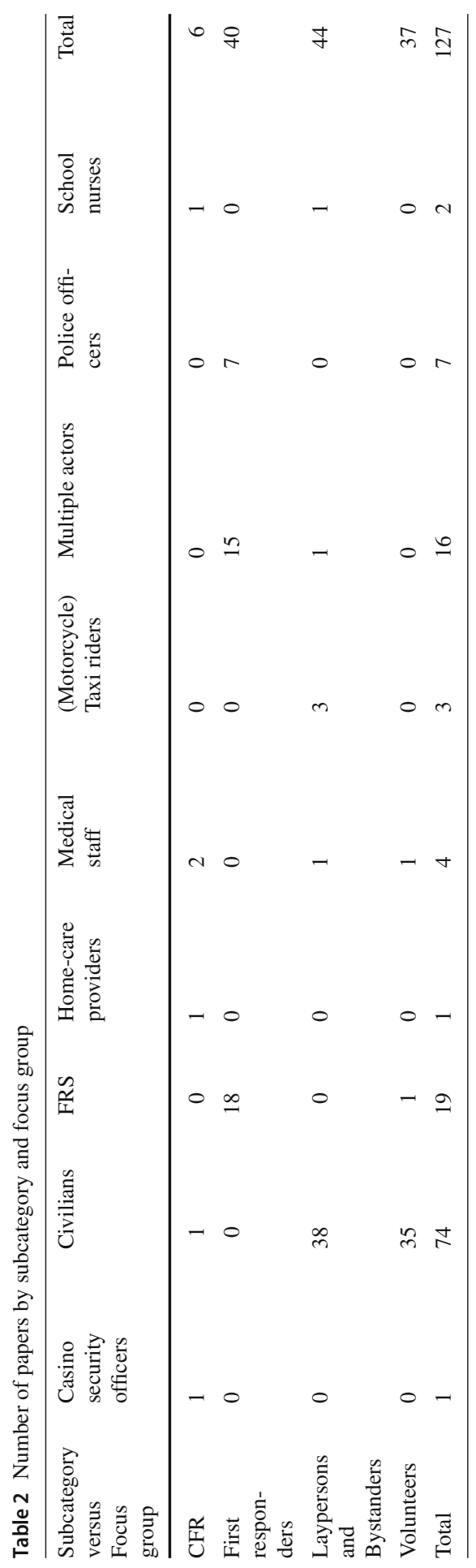


Table 3 Number of papers by continent and emergency type

\begin{tabular}{lccccr}
\hline Continent versus Emergency type & Bleeding & General & OHCA & Trauma & Total \\
\hline Africa & 0 & 1 & 0 & 7 & 8 \\
Asia and Oceania & 1 & 0 & 14 & 1 & 16 \\
Europe & 0 & 11 & 39 & 1 & 51 \\
North America & 19 & 5 & 17 & 4 & 45 \\
Unknown & 0 & 0 & 5 & 2 & 7 \\
Total & 20 & 17 & 75 & 15 & 127 \\
\hline
\end{tabular}

and Oceania followed by eight papers (six percent) from Africa, in which trauma is the most studied type of emergency. A lack of sufficient professional resources combined with road traffic injuries among major types of daily emergencies can be the reason for this focus in Africa. In seven papers (six percent) researchers have not stated on which country or region they have focused. We found no study focusing on South America. Even though some of the unknown studies could be related to South America, no country from this continent is explicitly mentioned in any of the reviewed works.

To see how the focus on different types of emergencies has changed over the years, we present Fig. 4. As shown in this figure, the number of studies related to trauma is almost the same across all years with a slight increase in 2019 and 2020. Bleeding has faced a rising interest since 2016 with the highest number of publications related to 2019. OHCA, on the other hand, has been having a different trend with fewer publications in the middle years (i.e., from 2009 to 2016) and the most publications in 2020.

\subsubsection{Cross tabulation}

With regard to the four main categories detailed in Sects. 2 and 3.1, in this section we present five cross tabulations: (1) emergency type versus subcategory, (2) subcategory versus data type, (3) data type versus methodology, (4) subcategory versus methodology, and (5) emergency type versus methodology. With the help of these tables we draw some insights regarding the literature on human resources.

In Fig. 5 we demonstrate both the cross tabulation of emergency type versus subcategory (as a numeric table) and the distribution of published papers in each subcategory by emergency type (as a diagram). As we can see from this figure, the focus of most papers is on OHCA, 29 papers considering the use of first responders to respond to this type of emergency, followed by volunteers (28 papers). Laypersons and bystanders are considered in nine papers in cases of trauma, but have been studied twice in case of bleeding (18 papers). These resources are considered in 14 papers with the focus on OHCA. CFR have been studied mostly in case of OHCA (four papers). Papers in the general category, for which authors of related papers have not clearly mentioned the type of emergency, have almost equally focused on volunteers (seven papers) and first responders (six papers), and have studied the use of laypersons and bystanders in three papers and CFR only in one paper. 
20

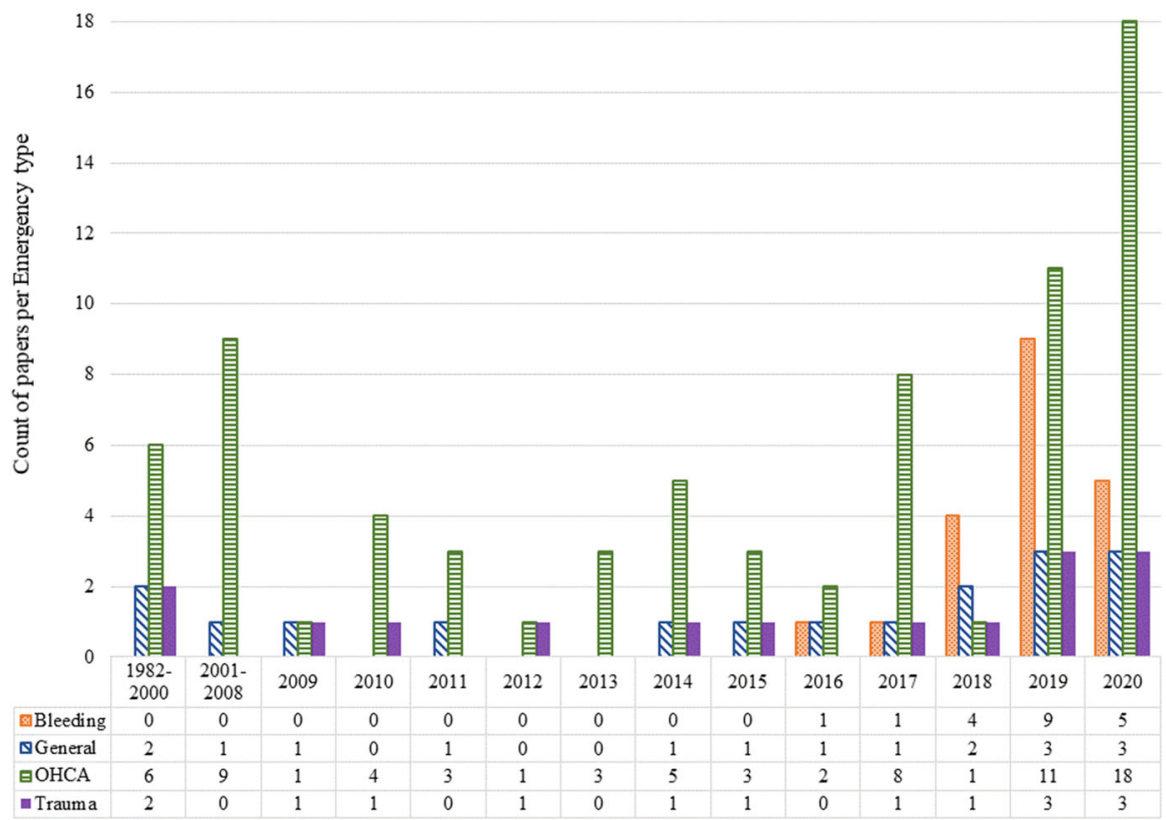

Fig. 4 Number of papers per year by emergency type

Based on these observations it seems that the use of first responders as well as volunteers in response to emergencies involving bleeding, when people usually apply tourniquet (or similar tools such as a belt), is an area to focus on. In cases in which shooting and knife attacks occur, first reponders, especially the police, are often the first at the scene of the event. Thus, if they already know how to stop a bleeding properly, it can help save lives of the patients. It is understandable that no study has focused on the use and dispatch of volunteers to manage bleeding. If the bleeding has been the result of a shooting, for example, the presence of volunteers at the scene can not only crowd the scene, but can also endanger their lives, especially if the situation is still on-going at the time of their arrival. Nevertheless, if the bleeding is a consequence of a common daily emergency (e.g., a bike accident), volunteers with the adequate skills for handling bleeding can be helpful. Overall, few studies have considered trauma as their emergency type. The use of different resource types for this emergency type is reasonable, for example in road traffic emergencies, in which trauma patients can be present. In such cases, first responders can be sent to the scene of the event if they will arrive sooner than the EMS to provide medical care. However, future work is needed to study if these resources (volunteers and first responders for bleeding cases and first responders in trauma cases) can contribute to saving lives, analogously to how it has been studied for OHCA.

We list all references based on subcategory and emergency type in Table 8. This table can be helpful for finding relevant references in the cross section of subcategories 


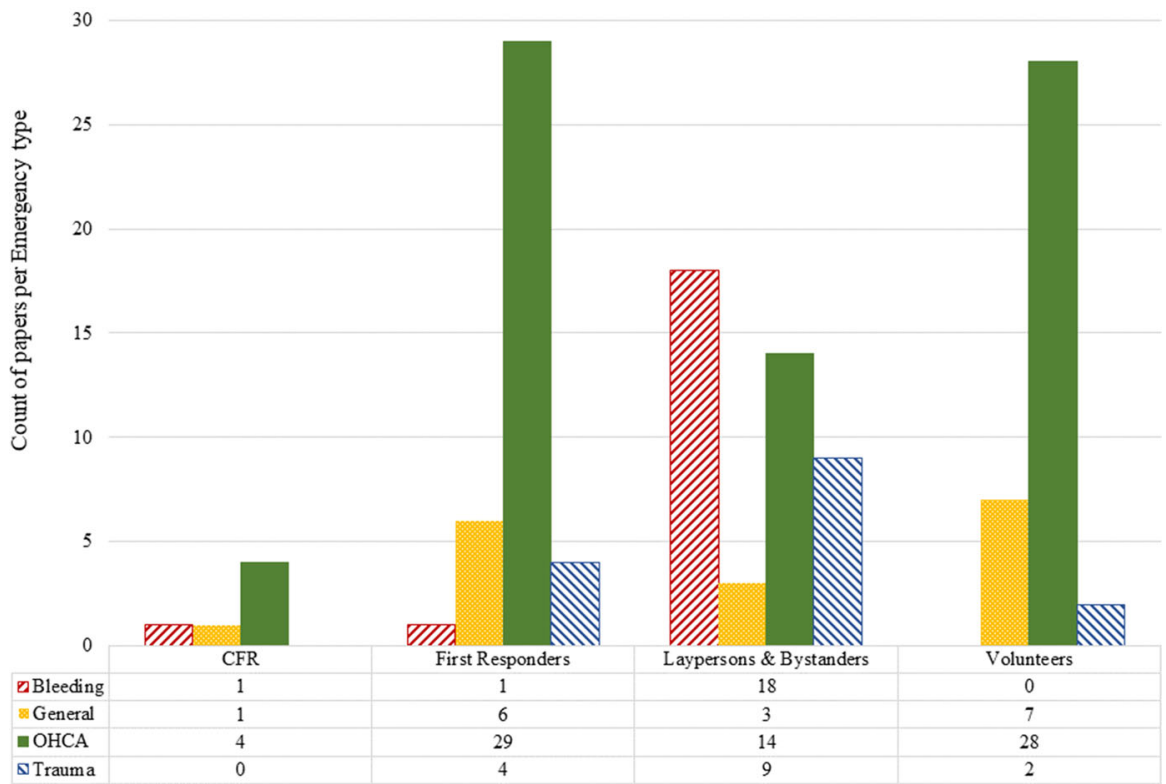

Fig. 5 Number of papers by emergency type per subcategory

Table 4 Number of papers by subcategory and data type

\begin{tabular}{llccr}
\hline Subcategory versus Data type & Hypothetical & Real & No data & Total \\
\hline CFR & 0 & 6 & 0 & 6 \\
First responders & 0 & 38 & 2 & 40 \\
Laypersons and Bystanders & 1 & 39 & 4 & 44 \\
Volunteers & 1 & 32 & 4 & 37 \\
Total & 2 & 115 & 10 & 127 \\
\hline
\end{tabular}

and emergency types. In this table each column is allocated to one type of emergency and each row represents a subcategory. In each cell we include papers published in different years that focus on a specific combination of subcategory and emergency type rather than the total number of publications. The last row and column give the total number of published papers per emergency type and subcategory, respectively.

Table 4 shows that the majority of papers (115) have used some type of real data. Researchers have gathered this data directly, for example through field research (i.e., primary data sets), or they have obtained it through archival data sets (i.e., secondary or tertiary data sets). In two papers researchers have used hypothetical data, while in 10 papers researchers have used no data.

In Table 5 we present the cross tabulation of data type versus primary methodology. In this table we have classified papers based on the method we found as the primary 
methodology used in that work. In some papers multiple methods have been used to obtain and analyze data. For instance, researchers have conducted a survey and then used simple statistical analysis techniques to quantify and further analyze the data. In addition, Table 5 includes both data gathering and data analysis techniques. Comparing the results in Tables 4 and 5 we can see that the 10 papers, in which no data has been used, are all related to review papers, of which one has focused on reviewing an appbased system (i.e., the GoodSAM app in the UK). By checking Table 5 we can also see that one of the papers using hypothetical data applies cost-effectiveness analysis and the other one mathematical programming as their methods. Some qualitative methods such as focus group, survey, and interview result in real data. However, the results of our review, as presented in Table 5, show that researchers have also (mostly) used real data for quantitative methods such as mathematical programming and simulation. Some additional observations include the following.

- The number of papers that have used one of the quantitative methods as their primary method accounts for $18 \%$ of all studies (i.e., 23 out of 127 papers). The high number of qualitative studies may be because within the medical research area conducting a trial or real-life simulation, or holding focus groups and interviews, in which people are involved in the study, are more common methods. In the healthcare area, even when a mathematical model is proposed and tested on real data, it should still be tested in a randomized trial in real life to ensure the analytically determined results are sound and reliable in practice as well. However, if prior to such a qualitative method (e.g., real-life experiment) the assumptions are modeled and tested quantitatively, it can potentially help reduce associated costs and increase the probability of success. In addition, using real data contributes to building a model or theory that can reflect the reality better and their results can be of higher trust for emergency managers and administrators.

- The methodology survey entails the entire process of data gathering (e.g., questionnaire, interview) and analyzing that data, while questionnaire is only a data gathering method. However, we found in the reviewed papers that researchers sometimes use survey and questionnaire interchangeably. Therefore, we have categorized papers using either of them under the same method category, survey.

In Table 6 we present the cross tabulation of subcategory versus methodology. In this table we present all methods used in each reviewed paper. For example, in one paper researchers have conducted a randomized control field experiment (listed under Real-life experiment) on volunteers and in case of trauma. Then these authors have used a survey and interviews to complement their research data, and eventually utilized statistical analysis to further analyze and draw their results. Therefore, methods used in this study are counted in all categories of real-life experiment, survey, interview, and statistical analysis, while we considered real-life experiment as the primary methodology of this work. It is noticeable that while only 17 papers used statistical analysis as their primary methodology (see Table 5), the number of papers that use this method in their work as a primary or complementary method sums up to 82. Our findings indicate that the majority of studies on laypersons and bystanders use reallife experiment (20 papers, of which 16 papers used it as their primary methodology), disregarding the use of statistical analysis as a complementary method. In the same 


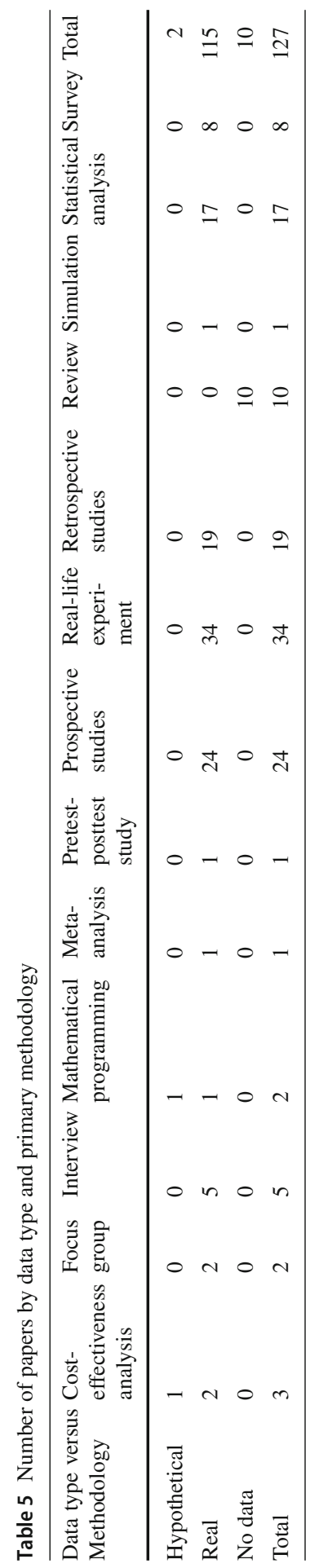


way, researchers have studied volunteers by using mainly real-life experiments (10 papers). The studies on first responders have mostly relied on prospective studies and retrospective studies, eight papers each.

Table 7 is a cross tabulation of emergency type versus methodology. In this table we present all methodologies used in each paper, similar to Table 6. If we disregard statistical analysis, which has served greatly as a complementary method (65 papers out of 82 papers), in case of bleeding, 12 studies have applied real-life experiment and no quantitative method has been used to study this emergency type. OHCA has been studied mostly using prospective studies and retrospective studies, 14 papers each and all as the primary method, and real-life experiment (13 papers, of which 10 papers used it as their primary methodology). However, researchers not only have applied other types of qualitative methods (e.g., survey (nine papers)) to investigate issues related to OHCA, but they have also used quantitative methods (e.g., mathematical programming (two paper) and simulation (one paper)). Trauma is studied qualitatively with statistical analysis serving as a complementary method, except in one paper, in which it has been used as a primary method.

\subsection{Equipment}

Besides human resources different types of equipment are utilized in pre-EMS services as well. Two main equipment types used in these services are AEDs and drones, also known as unmanned aerial vehicles (UAVs). We found 90 relevant papers on AEDs, 22 on drones, and 19 publications that simultaneously targeted drones and AEDs. In this section, we provide an overview of all these papers, studying equipment qualitatively or quantitatively. The papers using mathematical programming among quantitative works will be detailed in Sect. 3.3.

We can categorize AED-related papers under two main topics: (1) impact and usefulness of AEDs, and (2) location of AEDs. Researchers whose work categorizes under the first topic mostly have investigated the survival of OHCA patients. They have considered measures such as survival until discharge, and 30-day survival for patients for whom AEDs have been used. Researchers who have focused on the location of AEDs have investigated problems such as whether AEDs should be placed in public areas or not, whether AEDs should be located inside or outside of (high) buildings, or the impact of AED distributions and their access in urban versus rural areas. AEDs' accessibility and barriers such as awareness or willingness to use an AED have also been considered in the literature. Equipping basic life support ambulances with AEDs and transport of AEDs using public transportation are other investigated areas concerning AEDs.

Drones in pre-EMS services are used either to transport necessary equipment, such as AEDs and medicine, or to prevent people from drowning by helping them afloat. Another use of drones is to scan or photograph a scene or area in order to help with locating a drowning victim. Having drones transport AEDs to an emergency scene has been investigated as an addition or an alternative strategy to locate stationary AEDs.

In Table 9 we provide an overview of the number of papers published per year for equipment. While studies targeting the use of AEDs have already been published as 


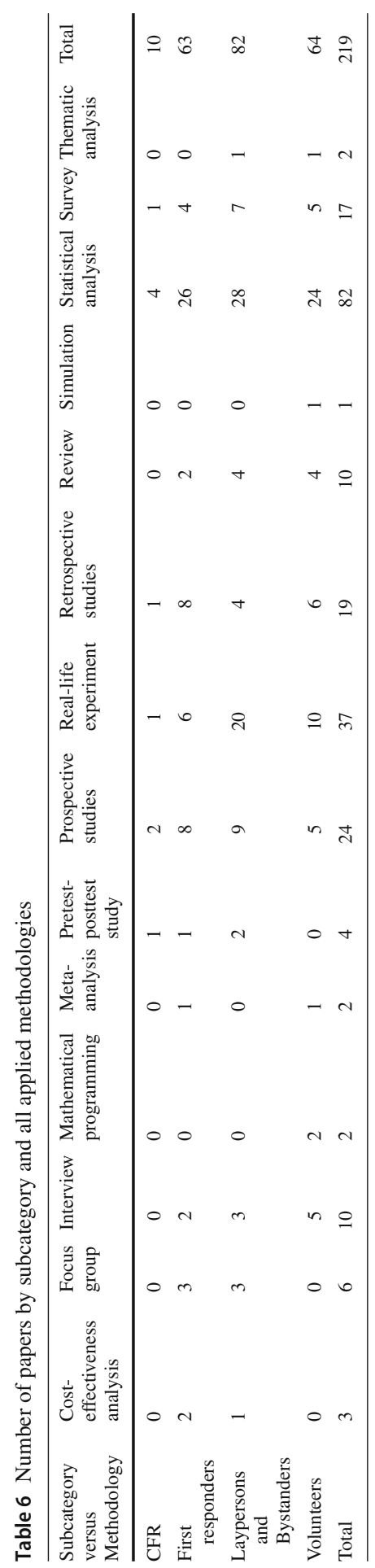




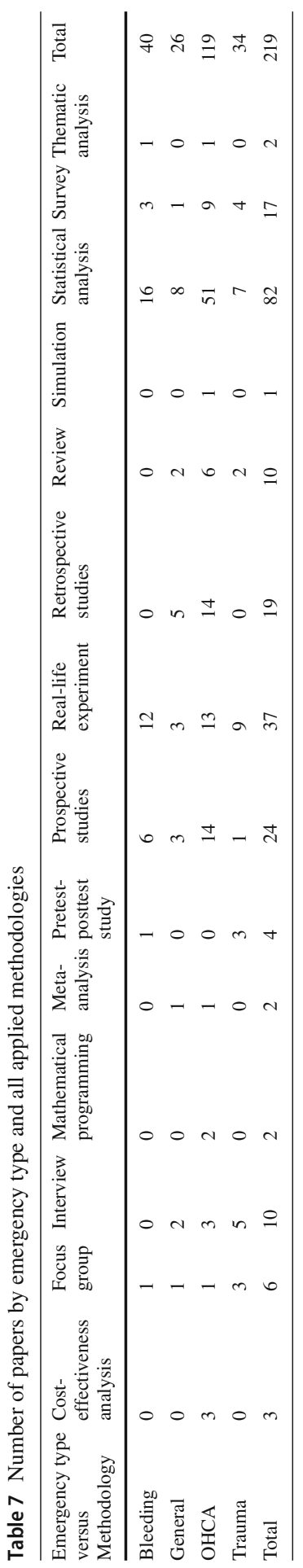




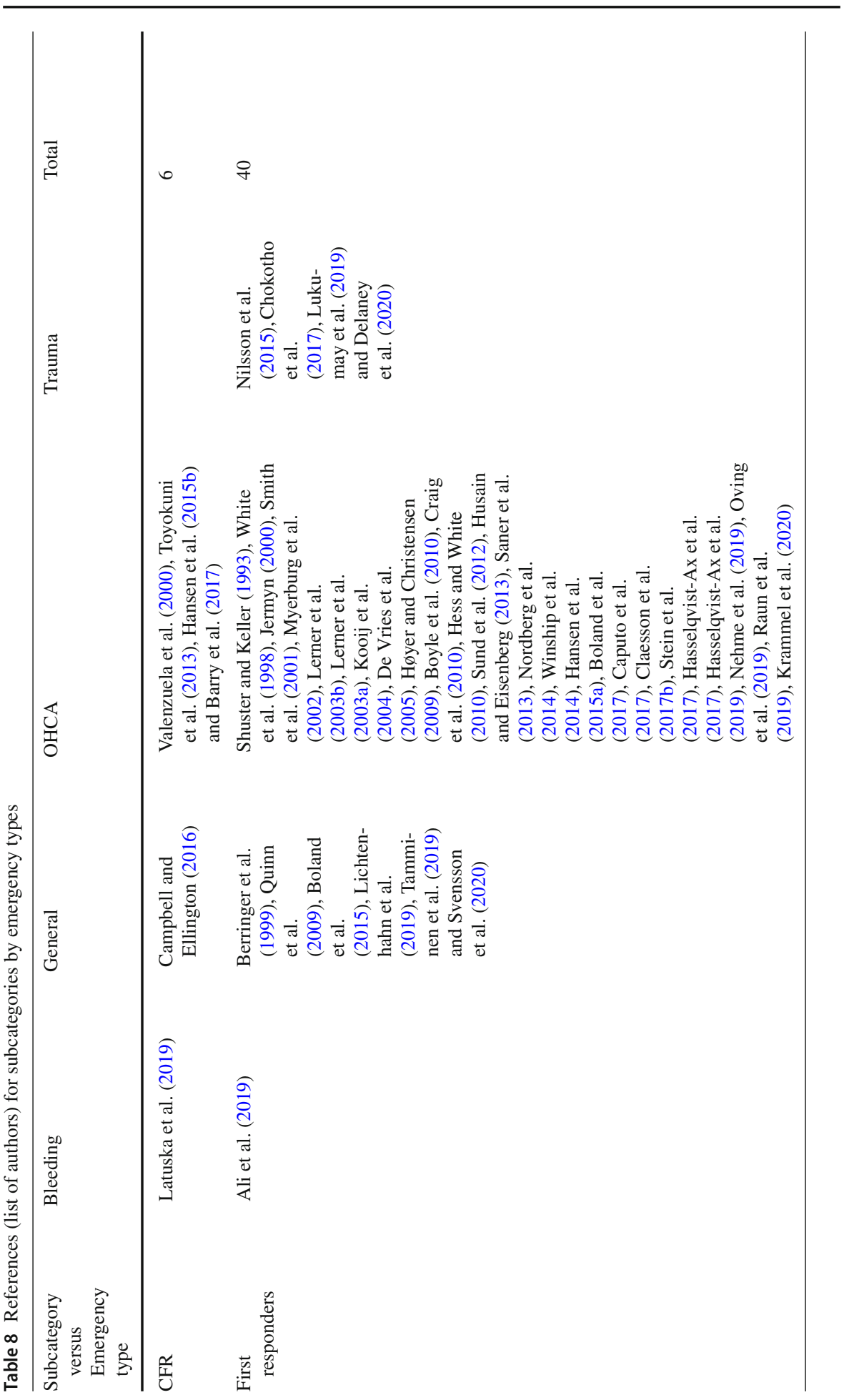

\section{Springer}




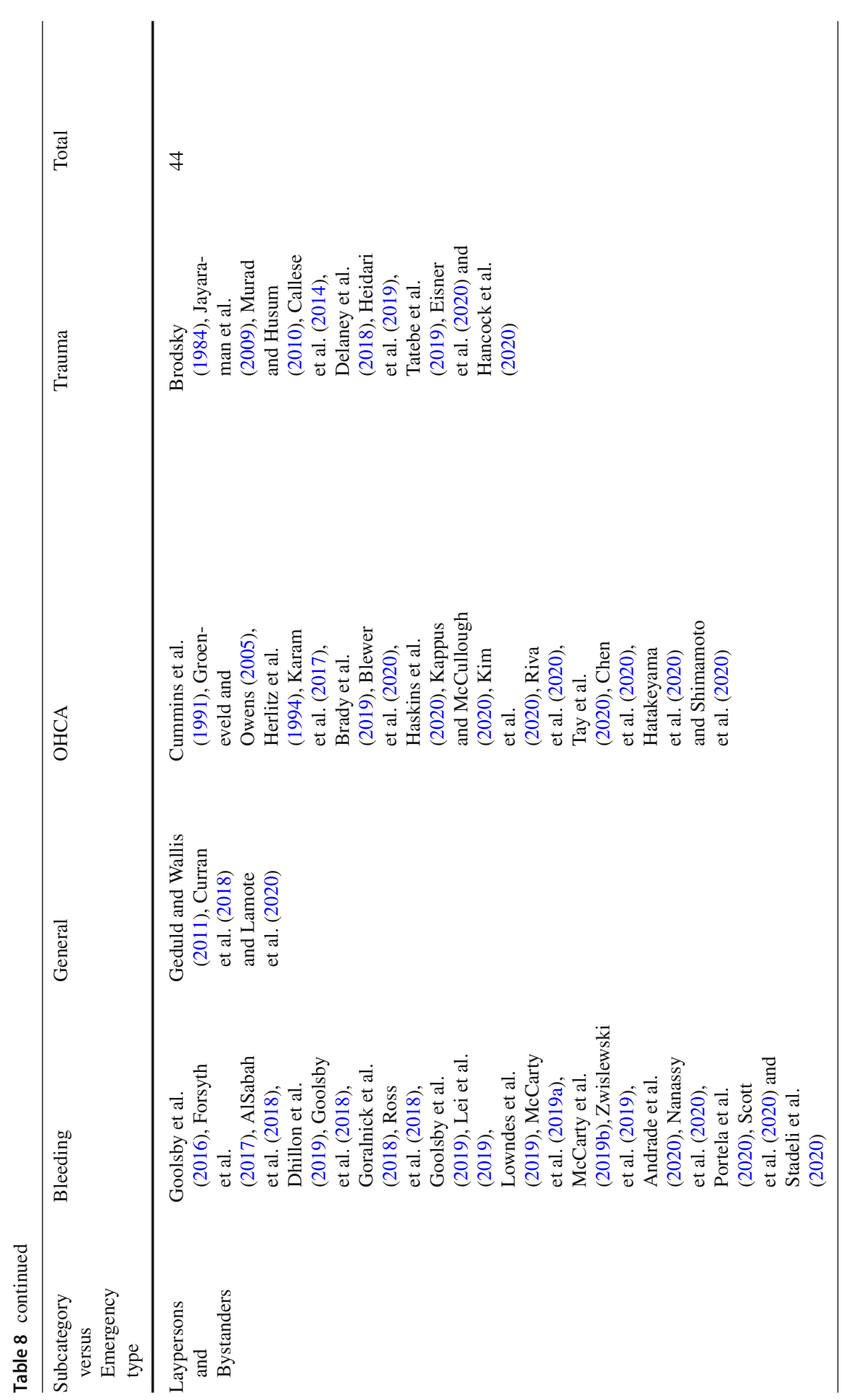




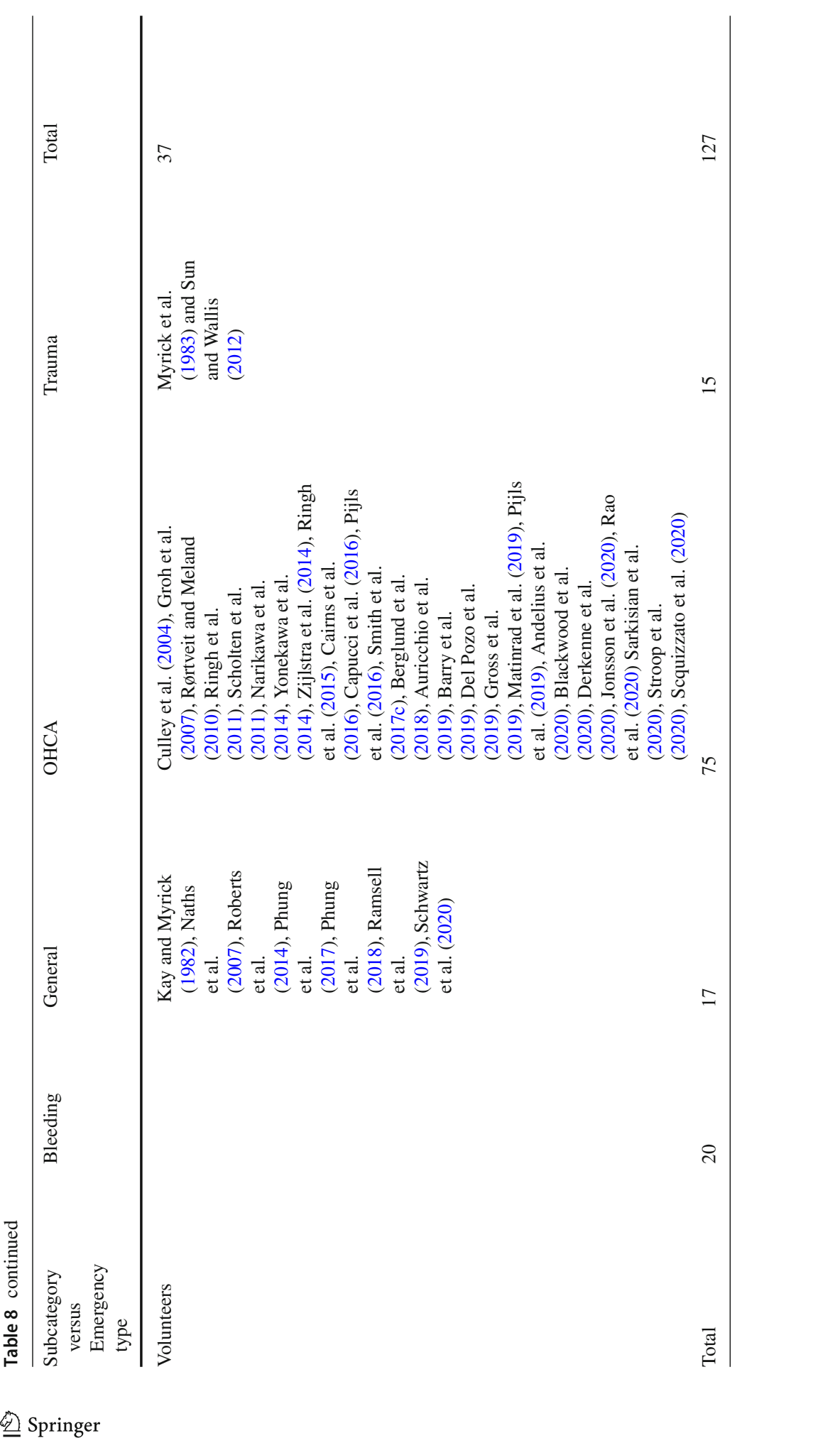


early as the 1980s, relevant publications on drones within pre-EMS services could only be found from 2015. The highest number of papers related to drones was published in 2020.

We show the number of publications for the equipment types per continent in Table 10. The majority of publications focusing on North America and Europe correspond to $63 \%$ (83 papers) of the studies. In North America, 28 papers focus on the USA, of which five papers have studied AEDs and drones and three papers drones. Within the European countries the highest numbers of publications target Denmark (eight papers), the Netherlands (seven papers), and Sweden (seven papers), with Denmark and the Netherlands focusing solely on the use of AEDs and Sweden on all three categories of equipment. All papers but one related to Asia and Oceania have focused on AEDs with the highest number of publications related to Japan and Taiwan (seven and five papers, respectively). We found only three publication for Africa (i.e., United Republic of Tanzania and Republic of Guinea). Similar to human resources, we found no paper for South America (see Sect. 3.1). In addition, 22 papers either did not state a country or targeted many countries worldwide (e.g., in a review paper) and are thus listed as "unknown" in the table.

Related to the type of emergencies, the AED-related papers (i.e., AEDs and drones, and $A D E s$ ) all targeted OHCA. Publications on drones, however, considered several emergency types including drowning (four papers), trauma (one paper), elderly patients falling (one paper), epilepsy (one paper), and OHCA (one paper). 14 papers addressed the use of drones in general.

In Table 11 we reference all publications on equipment with rows showing types of equipment and columns displaying the main methods used by researchers for these studies (i.e., qualitative, quantitative, review). As we focus on studies using mathematical programming in Sect. 3.3, we divide quantitative studies into Mathematical Programming and Other to make it easier to find references using mathematical programming. As shown in this table, 83 papers have used one type of quantitative method, while 31 paper have used a qualitative type of method. In addition, in 17 papers researchers have reviewed existing literature on different types of equipment.

We detail the methods used for all the references in Table 12. As we can see in this table, mathematical programming (38 papers) and statistical analysis (39 papers) are mostly used as the primary methodology. While mathematical programming is used in studies related to all equipment types, researchers have used statistical analysis primarily only for studies on AEDs. In addition, reviews (17 papers) have a relatively high number. It is interesting to note that researchers have used real-life experiments relatively balanced studying different equipment types (i.e., AEDs (four papers), drones (three papers), and AEDs and drones (four papers)). However, despite the usefulness and flexibility of simulation approaches, researcher have rarely used computer simulation as the primary methodology (these are categorized under mathematical programming in Table 12) and very few have used it as a complementary method (see Table 13).

In terms of the data types used by researchers, we found that in all but three publications, excluding reviews, real data was used. The three papers, in which hypothetical data was used, researchers have applied mathematical programming as their primary methodology. 


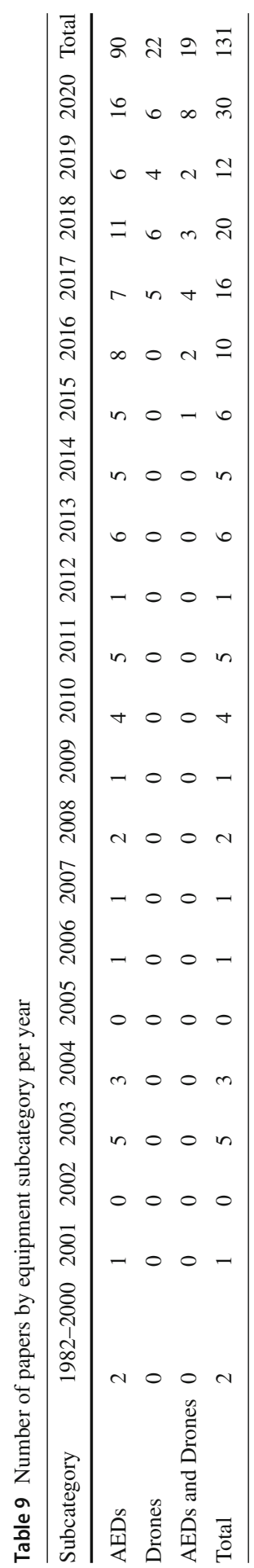


Table 10 Number of papers by continent and equipment subcategory

\begin{tabular}{lcccr}
\hline Continent versus Equipment subcategory & AEDs & Drones & AEDs and Drones & Total \\
\hline Africa & 0 & 3 & 0 & 3 \\
Asia and Oceania & 22 & 1 & 0 & 23 \\
Europe & 29 & 7 & 5 & 41 \\
North America & 29 & 5 & 8 & 42 \\
Unknown & 10 & 6 & 6 & 22 \\
Total & 90 & 22 & 19 & 131 \\
\hline
\end{tabular}

On the cross section of research on equipment and human resources in pre-EMS services, six papers related to drones transporting AEDs to an emergency explicitly mention the involvement of bystanders. With regard to literature on AEDs, different user groups including bystanders, volunteers, and first responders have been explicitly addressed. In one study researchers studied the use of AEDs by bystanders and discovered the importance of the AED user interface for the ability and success of a bystander to use an AED. In another study that reports on the use of AEDs in Europe, researchers found that out of the 36 studied European countries, in 11 of them only trained persons are allowed to use an AED. In addition, they stated that in 14 countries a few community responder programs exist. Also, one research group studied the location of AEDs for public use by bystanders and another one performed a survey with first responders from FRS concluding a lack of national standards and regulations for full integration of first responders programs into the EMS system.

\subsection{Quantitative studies in pre-EMS services}

In this section we take a closer look at the studies using mathematical programming for both equipment and human resources. In Table 13 we present an overview of the 41 publications using mathematical programming as their primary methodology (i.e., three papers related to human resources and 38 to equipment). In this table rows include pre-EMS services and columns types of data, modeling characteristics and approaches (i.e., methods), objective functions, planning levels, and planning problems.

The majority of the models have used a deterministic approach for strategic location planning, dismissing the uncertainties inherited in emergency cases. Such uncertainties are related to, for instance, travel times, the availability of human resources, or the functionality of equipment. Therefore, a deterministic model could have less capability in depicting the reality, and thus, be less useful for practice. Stochastic/probabilistic or robust optimization that could include these uncertainties have hardly been applied. Only six papers have addressed the operational planning level and no paper has considered a planning problem on the tactical level.

Most of the models have used coverage maximization as the objective function. As most of these studies focused on the placement of AEDs, including coverage as the objective function is reasonable. However, considering that the pre-EMS services are used in response to medical emergencies, it can be beneficial to consider survival 


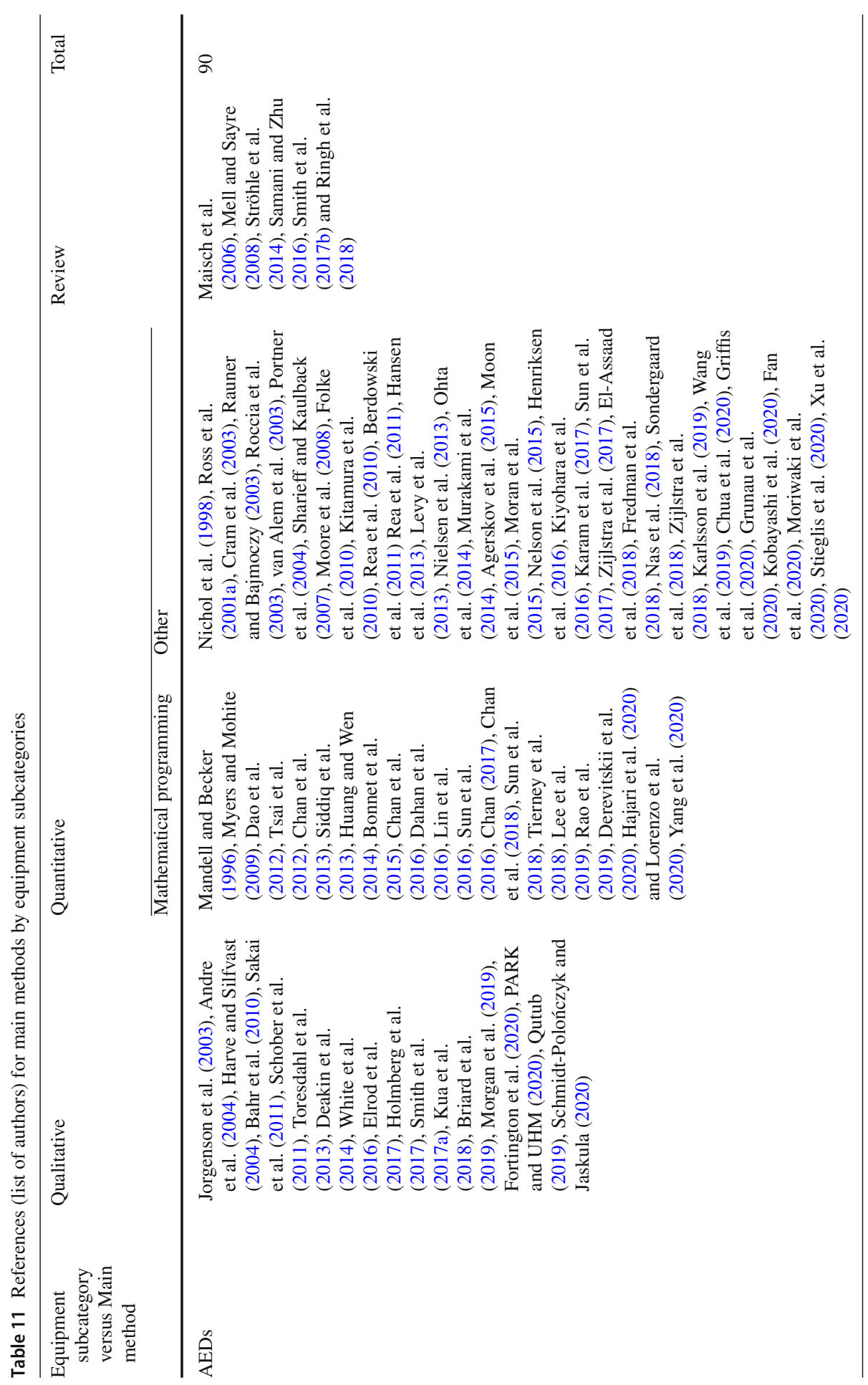




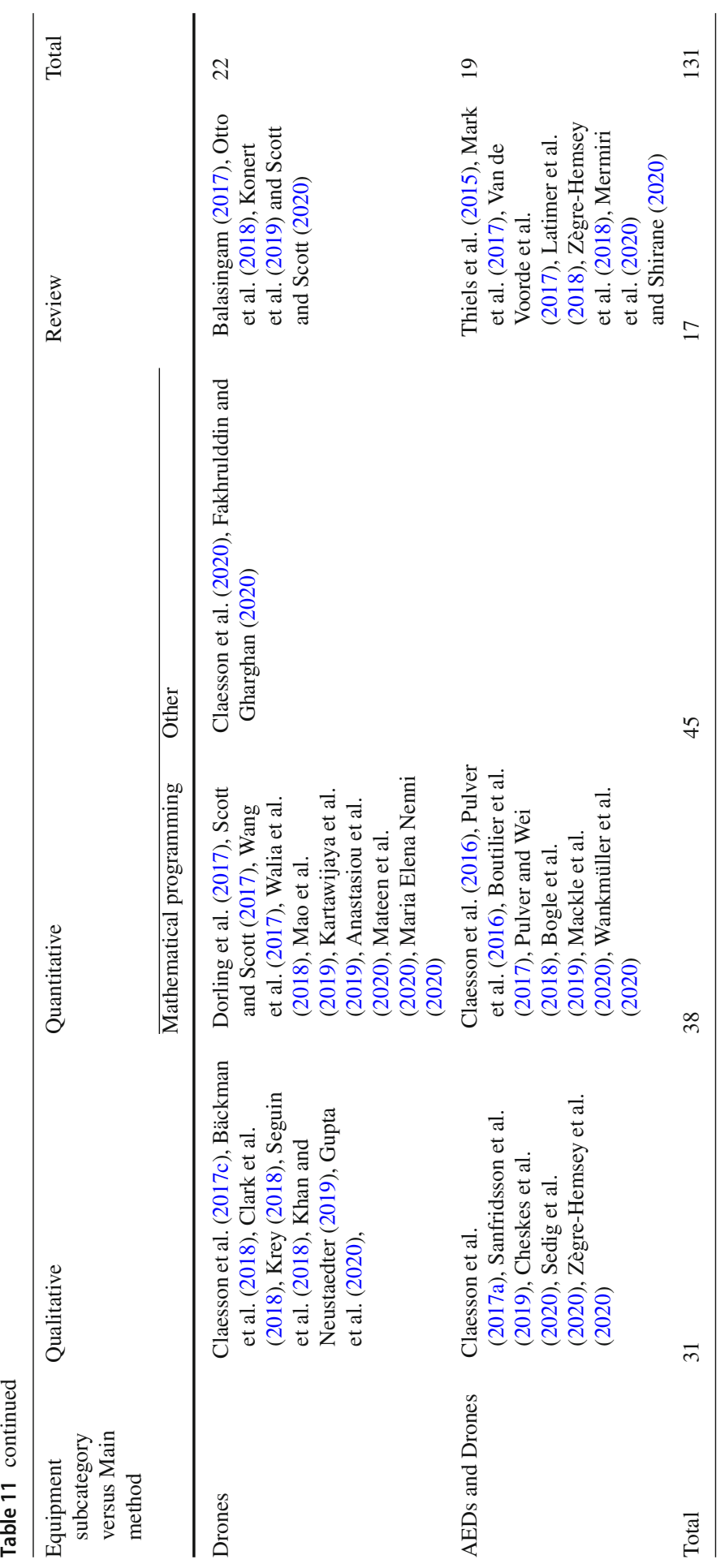




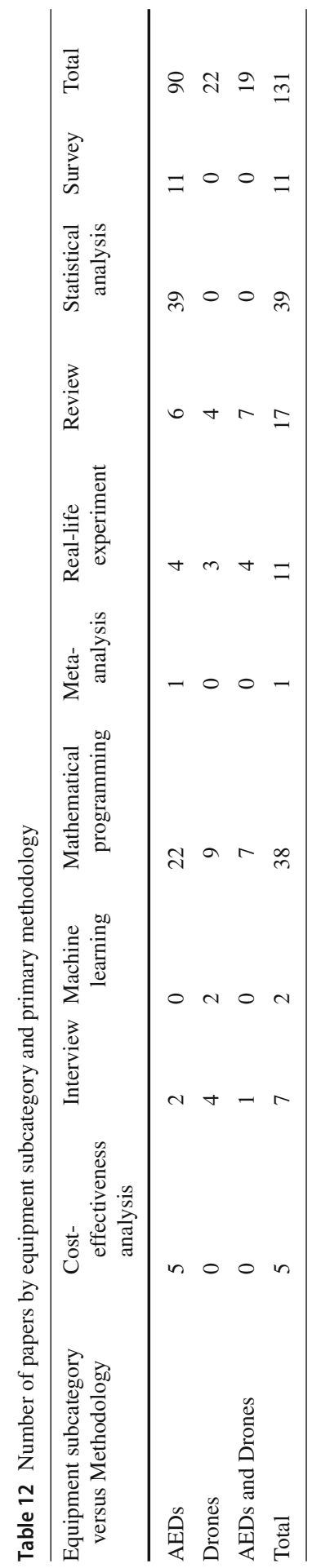




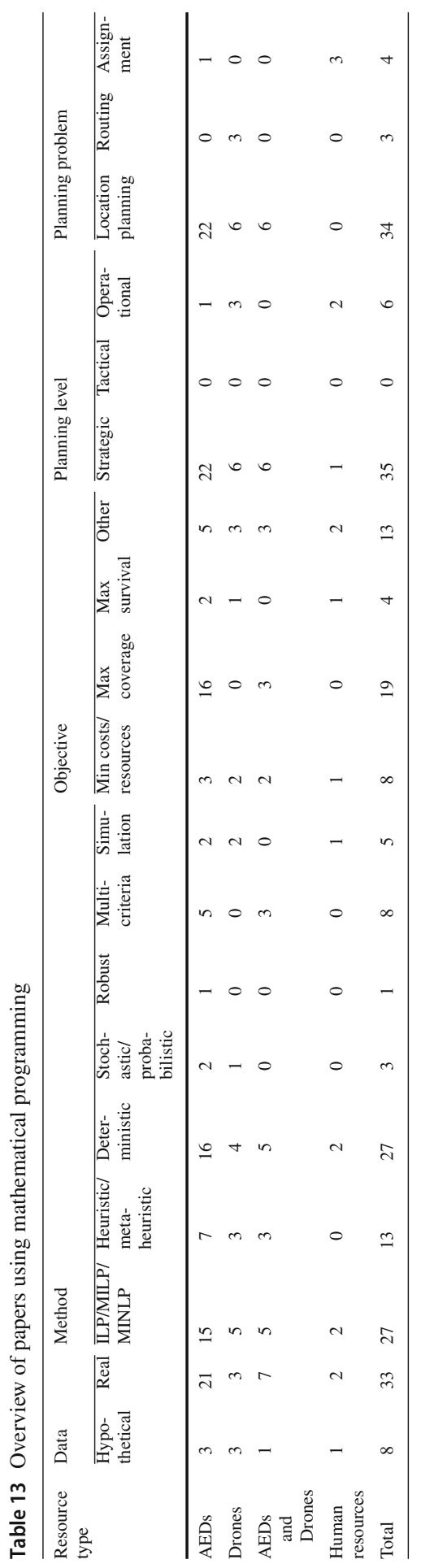


probability of patients in the modeling. Currently, only four out of 41 papers have considered survivability as their objective function. As shown by Erkut et al. (2008) for the ambulance location problem, the survival probability can be incorporated into the location problem as an objective function. 13 papers have used other objective functions, such as the time saved by using a drone or placing an AED compared to the arrival of the EMS or overall minimizing travel and response times.

The most common location model used by researchers is the maximal coverage location problem (MCLP), especially for the placement of AEDs. An alternative to this modeling could be the maximal survival location problem (MSLP) (Erkut et al. 2008). In this model, the focus is on the survivability of patients rather than coverage.

We found that simulation is used as a primary method only in three papers, one paper related to volunteers, one related to drones, and one to AEDs, and as a complementary method for two papers related to AEDs and drones (one for each). Mathematical models often need to make assumptions about reality in order to keep complexity and run times at a reasonable level that can still be handled. Simulations are thus a very important tool to analyze the computed solutions and account for the assumptions made in the models. They allow to vary input parameters and study the performance of the computed solutions (e.g., for increasing demand or time-dependent availability of volunteers).

While the majority of the researchers used real data, they usually focused on one city or region and did not test their approaches for different instances with varying characteristics.

Besides papers in which mathematical programming is used for modeling, we found statistical analysis as another dominating quantitative method used by researchers (see Tables 5 and 12). Researchers who have used statistical analysis have mostly applied one form of regression such as Poisson regression and logistic regression. They have (also) benefited from other statistical approaches such as descriptive statistics (e.g., mean, median, etc.), ROC analysis, Fisher test, $\chi^{2}$ test, Mann-Whitney test, and $t$ test.

\section{Pre-EMS services in different countries}

In order to provide additional insights on pre-EMS services for EMS managers and decision makers as well as for researchers, we also want to briefly review pre-EMS initiatives in practice with a special focus on mobile phone applications (apps) that assign first responders or volunteers to emergencies, such as OHCA, and might also display location of available AEDs. Apps as part of pre-EMS initiatives in practice play an important role to instantiate the services and they also offer opportunities to easily integrate operations research approaches to efficiently design and manage the logistics. As we found in the papers reviewed in this work, researchers focusing on different countries (Australia, Austria, Belgium, Canada, Chad, Denmark, Finland, France, Germany, Guatemala, Iraq, Ireland, Italy, Japan, Kuwait, Madagascar, Malawi, the Netherlands, Norway, Republic of Guinea, Singapore, Sierra Leone, South Africa, Scotland, Spain, Sweden, Switzerland, Tanzania, Taiwan, Uganda, United Republic of Tanzania, the UK, and the USA) have started studying the effects of the use of preEMS services in medical emergency responses. Some of these countries have already 
started at least one form of these services in practice. In Table 14 we provide an overview of operational pre-EMS services in some of these countries, as documented through literature, as well as functional apps, where applicable. In a recent publication in the journal Resuscitation, Scquizzato et al. (2020) listed first responders apps and AED maps in Europe, while they did not provide any references or further information and also limited their consideration to countries within Europe. Prior to the work of Scquizzato et al. (2020), Oving et al. (2019) have performed a survey with 47 OHCA experts from 29 countries with the aim of providing an overview of first responder systems for OHCA in Europe. The authors state that the result of their investigations show a wide variation of initiatives, and they recommend that future research should more strongly focus on survival.

It should be noted that the majority of reported apps in Table 14 have been found by an extensive additional search.

As we can see from Table 14, first responders is the most frequent and common type of human resources that is used in practice in medical emergency responses in several countries. Other than first responders, volunteers are the second most employed human resource of pre-EMS services. Some of the apps, such as GoodSAM (GoodSAM instant.help 2020) and iHelp, are functional across several countries, while some others are used by one country or region, for example St John First Responder App Western Australia is used in Western Australia. In some of these apps, users in vicinity of an OHCA patient who can perform basic life support or use an AED are alerted and given the locations of the patient and AEDs in their area that they should pick up (e.g., Sms-livräddare 2020). These apps notify users and usually, based on their predefined algorithms, assign them one of the two tasks of (1) going directly to the patient or (2) picking up an AED en route to the patient. They are mostly designed based on the distance between the patient and each user as well as the distance of AEDs to users and the patient. Other apps only provide information for basic life support and AED locations for bystanders or first responders to use. Some of these apps, such as GoodSAM, are used by multiple human resources (e.g., volunteers and first responders), while some others such as TrygFonden Hjerteløber are used only by volunteers. It should be pointed out that companies responsible for maintaining technical aspects of the apps can have different names than the apps, for example both apps Sms-livräddare and TrygFonden Hjerteløber are managed by the company HeartRunner Sweden AB (2020).

While a few apps exist that are used in more than one country, in some countries such as Germany, many different initiatives have formed that utilize individual apps. This diversity in apps withing one country makes it difficult to implement countrywide standards and best practices. In addition, volunteers living in one region and working in another one might need to use two different apps if they can attend to emergencies in both regions.

\section{Managerial implications}

To manage medical emergencies with limited resources and with the aim of upholding response time goals can become a complicated problem to solve. Depending on the 


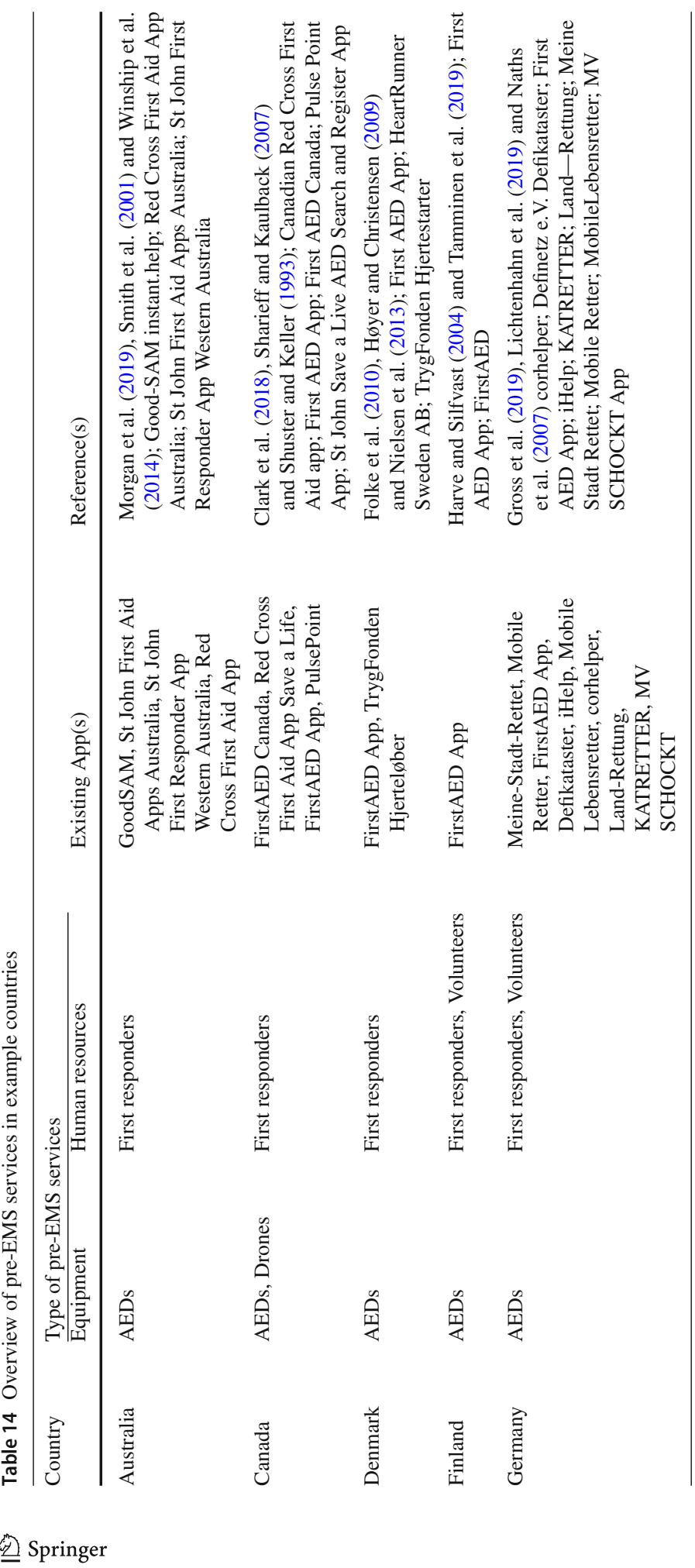




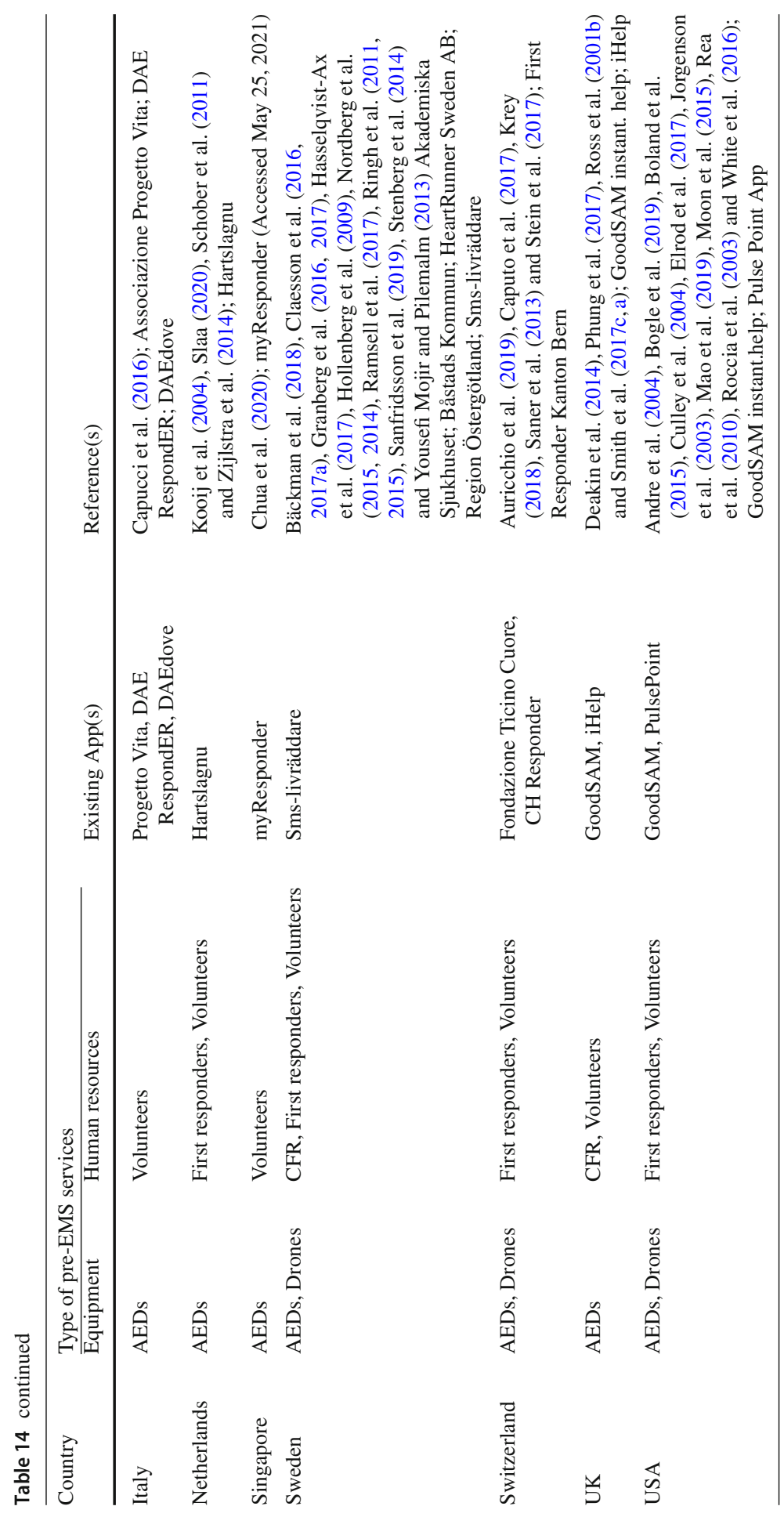


country, policies and processes for the management of EMS are set by one organization for the entire country or by separate organizations for each federal state or even EMS region in that country (e.g., Germany). Usually these organizations have already established processes for the management of their services. Introducing new types of resources into the current layout of these systems will most likely require changes in their current processes. The proposed changes can then potentially be successful in reaching the implementation stage if (1) they are designed and modeled in a way that they will support the existing processes and (2) it is possible to show managers that their inclusion into the system can be a course of action against a shortage of resources in the emergency system and a help for meeting the response time targets. Otherwise, the output of research proposing changes will not be accepted by EMS staff or decision makers.

Changing processes, especially digitizing them, is often very challenging. Research areas addressing change management and digital transformation could offer valuable insights and methods to define and support necessary steps, such as digital transformation strategies (Matt et al. 2015). Focusing on healthcare, Kash et al. (2014) have listed success factors for strategic change management and Pferzinger and Rammerstorfer (2017) suggested the use of Design Thinking methods to support digital transformation in healthcare. Four states of change for transforming healthcare organizations have been proposed by Golden (2006).

The question of which subcategory of human resources or equipment to concentrate on for each emergency type is of high importance for EMS managers. They are responsible for setting out policies and plans that can improve the response to the emergencies. Therefore, selecting appropriate resources that can contribute best to a good response can play a vital role in response improvements. In this review, we have grouped new types of resources for managing daily medical emergencies to two categories (Sect. 3). Then, in Sects. 3.1 and 3.2 we have provided seven subcategories on both human resources and equipment and discussed them further in detail. This categorization can help EMS managers to find relevant references on particular topics of interest.

Consider volunteers among the subcategories of human resources as an example. Their involvement in the medical emergency responses include several aspects such as: how to alert volunteers and to which emergencies, what impact their involvement in the response would have, what dispatch method can be used, and how technology can support it both in terms of equipment and platforms (e.g., apps). Emergency managers will be able to find relevant research papers and existing apps and make decisions based on the findings of those research.

Type of emergency is another essential aspect that has high importance for emergency managers. Based on our categorization, emergency managers can find emergency-specific research papers. While most of the pre-EMS resources can be used in response to all emergency types, the use of some of them for certain emergency types might be more beneficial and reasonable. In some regions, the occurrence of particular emergency types can be more frequent than others. For example, in areas with high social turbulence with a history of shooting and knifing incidents, a need for pre-EMS services that can handle bleeding is more essential. Another example is the regions in which EMS services are weak and road traffic injuries and trauma leads 
to many casualties (e.g., some African countries). In such regions, laypersons and bystanders can play an effective role in strengthening pre-hospital efforts. As another example, in a region with an elderly population, the probability of a heart attack or cardiac arrest might be higher and pre-EMS services suitable for responses to OHCA are needed. Moreover, in such areas often the number of home-care personnel is higher than in other areas, and thus, these people could act as CFR and be the primary human resource in those regions. Therefore, interest of an emergency manager in different emergency types in relation to pre-EMS resources may be based on the work region and responsibilities. It is nevertheless worth mentioning that an analysis of actual demand and needs in a region should precede the integration of pre-EMS services.

\section{Directions for future research}

Based on our findings from the review of 258 papers in this study, we make the following recommendations for future research. Our hope is that these recommendations can help researchers to address areas that have been less studied or need a different and new perspective. Consequently, over time, a body of work can form that represents a comprehensive and robust pre-EMS services literature. These recommendations can be categorized as those concerning methodology, modes of transportation, and integration of services. In the following, we present these recommendations in the order of these categories.

1. We found in our review that the majority of researchers, who have studied human resources, have used qualitative methods and methods that are common for the medical field. This leaves a noticeable gap for researchers of the OR domain to use different OR methods, such as optimization and simulation, to investigate the use of human resources in medical emergency responses.

2. Most of the researchers who have used optimization in their studies on any of the pre-EMS services, have developed a deterministic model. Although a deterministic setting makes the assumptions for modeling easier, it often makes the model less realistic. To depict the reality better and to deal with its associated uncertainties, researchers might want to consider the use of stochastic, probabilistic, or robust optimization as well as simulation-based optimization approaches.

3. In the existing body of works, a considerable number of studies are based on real-life experiments and simulations. However, not many researchers have used computer simulation as their methodology. Using computer simulation provides the opportunity to first test assumptions outside of the real world and without the use of real participants. Then, based on the successful settings of the computer simulation, a real-life experiment can be run. This can reduce the costs of experiments and potentially increase the chance of finding a successful setting. Simulation models have been successfully applied to planning problems within the classical EMS logistics, for example to analyze solutions of ambulance location models. Building simulation models for the use of AEDs and drones or incorporation of human resources in interventions in practice allows to analyze the potential impact and expected outcomes. 
4. Existing studies on AED locations often consider that these devices are placed at fixed locations using different modeling techniques, such as coverage models, and people have to find them and get them to the scene of emergencies. However, one promising way of using these devices for emergency response is mobile AEDs. In this setup, AEDs can be delivered to the emergency scene by different modes of transport (e.g., drones or taxis). While our review shows that some research addresses the use of drones, further research seems promising and other modes of transport should also be investigated.

5. In the current literature on drones as part of pre-EMS services, researchers have focused mostly on technical and logistical perspectives, such as location planning or routing. We recommend researching and defining a more detailed blue print for the use of drones. This could include, for example, the use of drones for pickup and delivery of all kinds of medical equipment to the scene of emergencies, especially to areas that have less stationary equipment or to mountainous regions that are harder to reach. The benefits of using drones, potentially together with logistics and service design, is a research area widely open for further investigation.

6. Studies on the use of pre-EMS services for various types of emergencies is an area with potential for further research. For instance, the use of first responders or volunteers in response to trauma or bleeding emergencies, respectively, from both a theoretical and a practical point of view, could be investigated.

7. Overall, a comparison of different pre-EMS services and their designs and an analysis of their applicability to various practical settings is missing in the literature. For instance, a comparison of first responders systems, potentially together with different location approaches for AEDs, would be of interest.

8. As we found that no research has studied pre-EMS services in South American countries, this is also an area for further studies especially from practical perspectives. Studies related to the application of pre-EMS services in one country might be applicable in another country, with some necessary modifications to fit the system of the other country. However, this applicability needs to be investigated using real data from the secondary country (e.g., a South American country) or the use of computer simulation.

9. The introduction of pre-EMS services can have benefits for both the society and professionals. These benefits can mean a reduction of response times, for example, or potentially increasing survival chances of patients. The better pre-EMS services are integrated into the emergency response system, while maintaining their identity as additional resources, the higher the chance of success for the response system. Therefore, further research regarding the integration of these services into the current professional emergency response system can lead to major benefits, especially for practice.

10. To implement or expand pre-EMS services in practice, studies on the requirements and technical aspects of systems are needed, such as apps and their back and front ends, to help medical emergency managers decide between different services and actual implementations.

11. More than 20 independent apps for first responders and volunteers to attend OHCAs, for example, are used in several countries worldwide. Future research could provide best practices and standards for the design and use of these apps. In 
addition, OR approaches could be integrated in the design and implementation of these apps, for example to efficiently assign volunteers to OHCAs and to decide who to pick up an AED or whether an AED comes by drone.

12. As we have found out in the screening of our initial search results, publications on the use of pre-EMS services in disasters and large-scale emergencies already exist. However, studies covering the use of these services across the emergency spectrum including both ends, daily emergencies and disasters, and the design of more general models can be an interesting and valuable future research direction.

\section{Summary and conclusions}

In this study, we have reviewed research on pre-EMS services that have been published in OR/OM or medical journals as well as conference proceedings until the end of the year 2020. We found a total of 258 papers published over a time span of 39 years (from 1982 to 2020). We focused our work on daily medical emergencies and presented an overview (macro-level analysis) of the existing literature in this field rather than giving a detailed (micro-level) analysis of a few individual papers. We hope that the output of this review will attract new researchers and provide valuable input and directions for future work to both researchers and medical emergency managers.

We categorized the papers based on the type of resource (i.e., human resources and equipment), type of emergency, type of data, and methodology. It is evident from the results of this review that researchers have mostly used qualitative methods to study human resources. While more researchers have used quantitative methods for equipment-related research, the overall focus on quantitative methods across all preEMS services has been relatively low. To test and validate the proposed hypotheses and models many researchers have used real data. So far, researchers have only considered the use of a single or very few resources for certain emergency types. Comparisons or studies on integrated use of several resources for multiple emergency types are still missing.

Acknowledgements The authors are grateful to the editor and the two anonymous reviewers for their valuable comments.

Funding Open access funding provided by Linköping University. This work was partly funded by the Swedish civil contingencies agency (MSB), through the Center for advanced research in emergency response (CARER).

\section{Declarations}

Conflict of interest The authors declare that they have no conflict of interest.

Open Access This article is licensed under a Creative Commons Attribution 4.0 International License, which permits use, sharing, adaptation, distribution and reproduction in any medium or format, as long as you give appropriate credit to the original author(s) and the source, provide a link to the Creative Commons licence, and indicate if changes were made. The images or other third party material in this article are included in the article's Creative Commons licence, unless indicated otherwise in a credit line to the material. If material is not included in the article's Creative Commons licence and your intended use is not permitted 
by statutory regulation or exceeds the permitted use, you will need to obtain permission directly from the copyright holder. To view a copy of this licence, visit http://creativecommons.org/licenses/by/4.0/.

\section{References}

Agerskov M, Nielsen AM, Hansen CM, Hansen MB, Lippert FK, Wissenberg M, Folke F, Rasmussen LS (2015) Public access defibrillation: great benefit and potential but infrequently used. Resuscitation 96:53-58

Akademiska Sjukhuset. In the wait of an ambulance [I väntan på ambulans (IVPA)]. https://www. akademiska.se/for-vardgivare/verksamhetsomraden/ambulanssjukvard/i-vantan-pa-ambulans-ivpa/. Accessed 28 June 2020

Ali F, Petrone P, Berghorn E, Jax J, Brathwaite CE, Brand D, D’Andrea KJ (2019) Teaching how to stop the bleed: does it work? A prospective evaluation of tourniquet application in law enforcement officers and private security personnel. Eur J Trauma Emerg Surg 1-5

AlSabah S, Al Haddad E, AlSaleh F (2018) Stop the bleed campaign: a qualitative study from our experience from the middle east. Ann Med Surg 36:67-70

Anastasiou A, Kolios P, Panayiotou C, Papadaki K (2020) Swarm path planning for the deployment of drones in emergency response missions. pp 456-465. https://doi.org/10.1109/ICUAS48674.2020.9213876

Andelius L, Malta Hansen C, Lippert FK, Karlsson L, Torp-Pedersen C, Kjær Ersbøll A, Køber L, Collatz Christensen H, Blomberg SN, Gislason GH et al (2020) Smartphone activation of citizen responders to facilitate defibrillation in out-of-hospital cardiac arrest. J Am Coll Cardiol 76(1):43-53

Andrade EG, Hayes JM, Punch LJ (2020) Stop the bleed: the impact of trauma first aid kits on post-training confidence among community members and medical professionals. Am J Surg 220(1):245-248

Andre AD, Jorgenson DB, Froman JA, Snyder DE, Poole JE (2004) Automated external defibrillator use by untrained bystanders: can the public-use model work? Prehosp Emerg Care 8(3):284-291

Aringhieri R, Bruni ME, Khodaparasti S, van Essen JT (2017) Emergency medical services and beyond: addressing new challenges through a wide literature review. Comput Oper Res 78:349-368

Associazione Progetto Vita. https://www.progetto-vita.eu/app/. Accessed 21 Oct 2020

Auricchio A, Gianquintieri L, Burkart R, Benvenuti C, Muschietti S, Peluso S, Mira A, Moccetti T, Caputo ML (2019) Real-life time and distance covered by lay first responders alerted by means of smartphoneapplication: implications for early initiation of cardiopulmonary resuscitation and access to automatic external defibrillators. Resuscitation 141:182-187

Båstads Kommun. http://www.bastad.se/omsorg-och-stod/ivpa-i-vantan-pa-ambulans/. Accessed 28 June 2020

Bahr J, Bossaert L, Handley A, Koster R, Vissers B, Monsieurs K (2010) AED in Europe. Report on a survey. Resuscitation 81(2):168-174

Balasingam M (2017) Drones in medicine-the rise of the machines. Int J Clin Pract 71(9):e12989

Barry T, Conroy N, Headon M, Egan M, Quinn M, Deasy C, Bury G (2017) The merit 3 project: alerting general practitioners to cardiac arrest in the community. Resuscitation 121:141-146

Barry T, Guerin S, Bury G (2019) Motivation, challenges and realities of volunteer community cardiac arrest response: a qualitative study of 'lay' community first responders. BMJ Open 9(8):e029015

Berdowski J, Blom MT, Bardai A, Tan HL, Tijssen JGP, Koster RW (2011) Impact of onsite or dispatched automated external defibrillator use on survival after out-of-hospital cardiac arrest. Circulation 124(20):2225-2232. https://doi.org/10.1161/circulationaha.110.015545

Berglund E, Claesson A, Nordberg P, Djärv T, Lundgren P, Folke F, Forsberg S, Riva G, Ringh M (2018) A smartphone application for dispatch of lay responders to out-of-hospital cardiac arrests. Resuscitation 126:160-165

Berringer R, Christenson J, Blitz M, Spinelli J, Freeman J, Maddess G, Rae S (1999) Medical role of first responders in an urban prehospital setting. Can J Emerg Med 1(2):93-98

Blackwood J, Mancera M, Bavery S, Carbon C, Daya M, VanKeulen B, Alteneder DN, Helm J, Robertson J, Charbonneau J et al (2020) Improving response to out-of-hospital cardiac arrest: the verified responder program pilot. Resuscitation 154:1-6

Blewer AL, Ho AFW, Shahidah N, White AE, Pek PP, Ng YY, Mao DR, Tiah L, Chia MYC, Leong BSH et al (2020) Impact of bystander-focused public health interventions on cardiopulmonary resuscitation and survival: a cohort study. Lancet Public Health 5(8):e428-e436 
Bogle BM, Rosamond WD, Snyder KT, Zègre-Hemsey JK (2019) The case for drone-assisted emergency response to cardiac arrest an optimized statewide deployment approach. N C Med J 80(4):204-212

Boland LL, Satterlee PA, Fernstrom KM, Hanson KG, Desikan P, LaCroix BK (2015) Advanced clinical interventions performed by emergency medical responder firefighters prior to ambulance arrival. Prehosp Emerg Care 19(1):96-102

Boland LL, Formanek MB, Harkins KK, Frazee CL, Kamrud JW, Stevens AC, Lick CJ, Yannopoulos D (2017) Minnesota heart safe communities: are community-based initiatives increasing pre-ambulance CPR and AED use? Resuscitation 119:33-36

Bonnet B, Dessavre DG, Kraus K, Ramirez-Marquez JE (2015) Optimal placement of public-access AEDs in urban environments. Comput Ind Eng 90:269-280

Boutilier JJ, Brooks SC, Janmohamed A, Byers A, Buick JE, Zhan C, Schoellig AP, Cheskes S, Morrison LJ, Chan TC (2017) Optimizing a drone network to deliver automated external defibrillators. Circulation 135(25):2454-2465

Boyle MJ, Williams B, Bibby C, Morton A, Huggins C (2010) The first 7 years of the metropolitan fire brigade emergency responder program - an overview of incidents attended. Open Access Emerg Med OAEM 2:77

Brady WJ, Mattu A, Slovis CM (2019) Lay responder care for an adult with out-of-hospital cardiac arrest. N Engl J Med 381(23):2242-2251

Briard JN, Grou-Boileau F, Bashtaly AE, Spenard C, de Champlain F, Homier V (2019) Automated external defibrillator geolocalization with a mobile application, verbal assistance or no assistance: a pilot randomized simulation (AED g-map). Prehospital Emerg Care 23(3):420-429

Brodsky H (1984) The bystander in highway injury accidents. Soc Sci Med 19(11):1213-1216

Bäckman A, Hollenberg J, Svensson L, Ringh M, Nordberg P, Djärv T, Forsberg S, Hernborg O, Claesson A (2018) Drones for provision of flotation support in simulated drowning. Air Med J 37(3):170-173

Bélanger V, Ruiz A, Soriano P (2019) Recent optimization models and trends in location, relocation, and dispatching of emergency medical vehicles. Eur J Oper Res 272(1):1-23

Using simulation to assess cardiac first-responder schemes exhibiting stochastic and spatial complexities. In: Operational Research for Emergency Planning in Healthcare: Volume 2, Springer, pp 48-68

Callese TE, Richards CT, Shaw P, Schuetz SJ, Issa N, Paladino L, Swaroop M (2014) Layperson trauma training in low-and middle-income countries: a review. J Surg Res 190(1):104-110

Campbell A, Ellington M (2016) Reducing time to first on scene: an ambulance-community first responder scheme. Emerg Med Int 2016:7. https://doi.org/10.1155/2016/1915895

Canadian Red Cross First Aid app. https://www.redcross.ca/training-and-certification/first-aid-tips-andresources/first-aid-app. Accessed 18 Oct 2020

Capucci A, Aschieri D, Guerra F, Pelizzoni V, Nani S, Villani GQ, Bardy GH (2016) Community-based automated external defibrillator only resuscitation for out-of-hospital cardiac arrest patients. Am Heart J 172:192-200

Caputo ML, Muschietti S, Burkart R, Benvenuti C, Conte G, Regoli F, Mauri R, Klersy C, Moccetti T, Auricchio A (2017) Lay persons alerted by mobile application system initiate earlier cardio-pulmonary resuscitation: a comparison with SMS-based system notification. Resuscitation 114:73-78

CARER. Center for advanced research in emergency response (carer). https://liu.se/en/research/center-foradvanced-research-in-emergency-response. Accessed 12 July 2021

Chan TC, Li H, Lebovic G, Tang SK, Chan JY, Cheng HC, Morrison LJ, Brooks SC (2013) Identifying locations for public access defibrillators using mathematical optimization. Circulation 127(17):18011809

Chan TC, Shen ZJM, Siddiq A (2018) Robust defibrillator deployment under cardiac arrest location uncertainty via row-and-column generation. Oper Res 66(2):358-379

Chan TCY (2017) Rise and shock: optimal defibrillator placement in a high-rise building. Prehosp Emerg Care 21(3):309-314

Chan TCY, Demirtas D, Kwon RH(2016) Optimizing the deployment of public access defibrillators. Manage Sci 62(12):3617-3635

Chen YC, Yu SH, Chen WJ, Huang LC, Chen CY, Shih HM (2020) Dispatcher-assisted cardiopulmonary resuscitation: disparity between urban and rural areas. Emerg Med Int 2020:7. https://doi.org/10.1155/ 2020/9060472

Cheskes S, McLeod SL, Nolan M, Snobelen P, Vaillancourt C, Brooks SC, Dainty KN, Chan TCY, Drennan IR (2020) Improving access to automated external defibrillators in rural and remote settings: a drone delivery feasibility study. J Am Heart Assoc. https://doi.org/10.1161/JAHA.120.016687 
Chokotho L, Mulwafu W, Singini I, Njalale Y, Maliwichi-Senganimalunje L, Jacobsen KH (2017) First responders and prehospital care for road traffic injuries in Malawi. Prehosp Disaster Med 32(1):14

Chua S, Ng YY, Ong M (2020) Getting r-AEDI to save lives in Singapore. Singapore Med J 61(2):60-62. https://doi.org/10.11622/smedj.2020013

Claesson A, Fredman D, Svensson L, Ringh M, Hollenberg J, Nordberg P, Rosenqvist M, Djarv T, Österberg S, Lennartsson J et al (2016) Unmanned aerial vehicles (drones) in out-of-hospital-cardiac-arrest. Scand J Trauma Resuscit Emerg Med 24(1):124

Claesson A, Bäckman A, Ringh M, Svensson L, Nordberg P, Djärv T, Hollenberg J (2017) Time to delivery of an automated external defibrillator using a drone for simulated out-of-hospital cardiac arrests vs emergency medical services. JAMA 317(22):2332-2334

Claesson A, Herlitz J, Svensson L, Ottosson L, Bergfeldt L, Engdahl J, Ericson C, Sandén P, Axelsson C, Bremer A (2017) Defibrillation before ems arrival in western Sweden. Am J Emerg Med 35(8):10431048

Claesson A, Svensson L, Nordberg P, Ringh M, Rosenqvist M, Djarv T, Samuelsson J, Hernborg O, Dahlbom P, Jansson A, Hollenberg J (2017) Drones may be used to save lives in out of hospital cardiac arrest due to drowning. Resuscitation 114:152-156

Claesson A, Schierbeck S, Hollenberg J, Forsberg S, Nordberg P, Ringh M, Olausson M, Jansson A, Nord A (2020) The use of drones and a machine-learning model for recognition of simulated drowning victims_a feasibility study. Resuscitation 156:196-201. https://doi.org/10.1016/j.resuscitation.2020. 09.022

Clark DG, Ford JD, Tabish T (2018) What role can unmanned aerial vehicles play in emergency response in the Arctic: a case study from Canada. PLoS ONE 13(12):1-16

Coppola DP (2006) Introduction to international disaster management. Elsevier, Amsterdam

corhelper. https://corhelper.de/. Accessed 18 Oct 2020

Craig AM, Verbeek PR, Schwartz B (2010) Evidence-based optimization of urban firefighter first response to emergency medical services 9-1-1 incidents. Prehosp Emerg Care 14(1):109-117

Cram P, Vijan S, Fendrick AM (2003) Cost-effectiveness of automated external defibrillator deployment in selected public locations. J Gen Intern Med 18(9):745-754

Culley LL, Rea TD, Murray JA, Welles B, Fahrenbruch CE, Olsufka M, Eisenberg MS, Copass MK (2004) Public access defibrillation in out-of-hospital cardiac arrest: a community-based study. Circulation 109(15):1859-1863

Cummins RO, Ornato JP, Thies WH, Pepe PE (1991) Improving survival from sudden cardiac arrest: the "chain of survival" concept. A statement for health professionals from the advanced cardiac life support subcommittee and the emergency cardiac care committee, American Heart Association. Circulation 83(5):1832-1847

Curran J, Ritchie SD, Beardy J, VanderBurgh D, Born K, Lewko J, Orkin AM (2018) Conceptualizing and managing medical emergencies where no formal paramedical system exists: perspectives from a remote indigenous community in Canada. Int J Environ Res Public Health 15(2):267

DAE RespondER. https://www.118er.it/dae/info.asp. Accessed 18 Oct 2020

DAEdove. http://www.daedove.it/. Accessed 18 Oct 2020

Dahan B, Jabre P, Karam N, Misslin R, Bories MC, Tafflet M, Bougouin W, Jost D, Beganton F, Beal G, Pelloux P, Marijon E, Jouven X (2016) Optimization of automated external defibrillator deployment outdoors: an evidence-based approach. Resuscitation 108:68-74

Dao THD, Zhou Y, Thill JC, Delmelle E (2012) Spatio-temporal location modeling in a 3d indoor environment: the case of AEDS as emergency medical devices. Int J Geogr Inf Sci 26(3):469-494

De Vries W, Van Alem AP, De Vos R, Van Oostrom J, Koster RW (2005) Trained first-responders with an automated external defibrillator: how do they perform in real resuscitation attempts? Resuscitation 64(2):157-161

Deakin CD, Shewry E, Gray HH (2014) Public access defibrillation remains out of reach for most victims of out-of-hospital sudden cardiac arrest. Heart 100(8):619-623. https://doi.org/10.1136/heartjnl-2013305030

Definetz eV Defikataster. http://definetz.online/defikataster-hp. Accessed 18 Oct 2020

Del Pozo A, Villalobos F, Rey-Reñones C, Granado E, Sabaté D, Poblet C, Calvet A, Basora J, Castro A, Flores G (2019) Effectiveness of a network of automatically activated trained volunteers on the reduction of cardiopulmonary resuscitation manoueuvers initiation time: study protocol. BMC Public Health 19(1):1-5 
Delaney PG, Bamuleke R, Lee YJ (2018) Lay first responder training in eastern Uganda: leveraging transportation infrastructure to build an effective prehospital emergency care training program. World $\mathrm{J}$ Surg 42(8):2293-2302

Delaney PG, Figueroa JA, Eisner ZJ, Andrade REH, Karmakar M, Scott JW, Raghavendran K (2020) Designing and implementing a practical prehospital emergency trauma care curriculum for lay first responders in Guatemala. Trauma Surg Acute Care Open 5(1):e000409

Derevitskii I, Kogtikov N, Lees M, Cai W, Ong M (2020) Risk-based AED placement-Singapore Case, pp 577-590

Derkenne C, Jost D, Roquet F, Dardel P, Kedzierewicz R, Mignon A, Travers S, Frattini B, Prieux L, Rozenberg E et al (2020) Mobile smartphone technology is associated with out-of-hospital cardiac arrest survival improvement: the first year "greater Paris fire brigade" experience. Acad Emerg Med 27(10):951-962

Dhillon NK, Dodd BA, Hotz H, Patel KA, Linaval NT, Margulies DR, Ley EJ, Barmparas G (2019) What happens after a stop the bleed class? The contrast between theory and practice. J Surg Educ 76(2):446452

Dorling K, Heinrichs J, Messier GG, Magierowski S (2017) Vehicle routing problems for drone delivery. IEEE Trans Syst Man Cybern Syst 47(1):70-85

DRK-Landesverb and Baden-Württemberg eV, DRK-Landesverband Badisches Rotes Kreuz eV (2018) Positionen zur Zukunft des Rettungsdienstes in Baden-Württemberg. Technical report

Eisner ZJ, Delaney PG, Thullah AH, Amanda JY, Timbo SB, Koroma S, Sandy K, Sesay AD, Turay P, Scott JW et al (2020) Evaluation of a lay first responder program in Sierra Leone as a scalable model for prehospital trauma care. Injury 51(11):2565-2573

El-Assaad I, Al-Kindi SG, McNally B, Vellano K, Worley S, Tang AS, Aziz PF, Group CS, et al. (2018) Automated external defibrillator application before EMS arrival in pediatric cardiac arrests. Pediatrics 142(4): e20171903. https://doi.org/10.1542/peds.2017-1903

Elrod JB, Merchant R, Daya M, Youngquist S, Salcido D, Valenzuela T, Nichol G (2017) Public health surveillance of automated external defibrillators in the usa: protocol for the dynamic automated external defibrillator registry study. BMJ Open 7(3). https://bmjopen.bmj.com/content/7/3/e014902

Erkut E, Ingolfsson A, Erdoğan G (2008) Ambulance location for maximum survival. Naval Res Log (NRL) 55(1):42-58

Fakhrulddin SS, Gharghan SK (2020) An elderly first aid system based-fall detection and unmanned aerial vehicle. IOP Conf Ser Mater Sci Eng 745:012096. https://doi.org/10.1088/1757-899x/745/1/012096

Fan M, Fan K, Leung L (2020) Walking route-based calculation is recommended for optimizing deployment of publicly accessible defibrillators in urban cities. J Am Heart Assoc 9(2):e014398. https://doi.org/ 10.1161/JAHA.119.014398

First AED App. https://firstaed.com/en/. Accessed 18 Oct 2020

First AED Canada. https://firstaedcanada.ca/responder-app/. Accessed 18 Oct 2020

First Responder Kanton Bern. https://www.firstresponder.be/. Accessed 18 Oct 2020

FirstAED. https://www.healthcaredenmark.dk/news/firstaed-introduces-successful-app-in-finland/. Accessed 18 Oct 2020

Folke F, Gislason GH, Lippert FK, Nielsen SL, Weeke P, Hansen ML, Fosbøl EL, Andersen SS, Rasmussen S, Schramm TK, Køber L, Torp-Pedersen C (2010) Differences between out-of-hospital cardiac arrest in residential and public locations and implications for public-access defibrillation. Circulation 122(6):623-630

Forsyth KL, Lowndes BR, Prytz E, Jonson CO, Sztajnkrycer MD, Heller SF, Hallbeck MS, Blocker RC (2017) Improving instructions to stop the bleed. In: Proceedings of the Human Factors and Ergonomics Society Annual Meeting, SAGE Publications Sage CA: Los Angeles, CA, vol 61, pp 588-592

Fortington LV, Bekker S, Finch CF (2020) Integrating and maintaining automated external defibrillators and emergency planning in community sport settings: a qualitative case study. Emerg Med J 37(10):617622. https://doi.org/10.1136/emermed-2019-208781

Fothergill RT, Watson LR, Chamberlain D, Virdi GK, Moore FP, Whitbread M (2013) Increases in survival from out-of-hospital cardiac arrest: a five year study. Resuscitation 84(8):1089-1092

Fredman D, Ringh M, Svensson L, Hollenberg J, Nordberg P, Djärv T, Hasselqvist-Ax I, Wagner H, Forsberg S, Nord A, Jonsson M, Claesson A (2018) Experiences and outcome from the implementation of a national Swedish automated external defibrillator registry. Resuscitation 130:73-80

Geduld H, Wallis L (2011) Taxi driver training in Madagascar: the first step in developing a functioning prehospital emergency care system. Emerg Med J 28(9):794-796 
Golden B (2006) Transforming healthcare organizations. Healthc Q 10(10-9):4

GoodSAM instanthelp. https://www.goodsamapp.org/assets/pdf/Brochure.pdf. Accessed 18 Oct 2020

Goolsby C, Chen E, Branting A, Weissbrod E, David J, Moore K, Olsen C (2016) Analysis of layperson tourniquet application using a novel color-coded device. Disaster Med Public Health Prep 10(2):274280

Goolsby C, Rojas L, Moore K, Kretz E, Singletary E, Klimczak V, Charlton N (2019) Layperson ability and willingness to use hemostatic dressings: a randomized, controlled trial. Prehosp Emerg Care 23(6):795-801

Goolsby CA, Strauss-Riggs K, Klimczak V, Gulley K, Rojas L, Godar C, Raiciulescu S, Kellermann AL, Kirsch TD (2018) Brief, web-based education improves lay rescuer application of a tourniquet to control life-threatening bleeding. AEM Educ Train 2(2):154-161

Goralnick E, Chaudhary MA, McCarty JC, Caterson EJ, Goldberg SA, Herrera-Escobar JP, McDonald M, Lipsitz S, Haider AH (2018) Effectiveness of instructional interventions for hemorrhage control readiness for laypersons in the public access and tourniquet training study (Patts): a randomized clinical trial. JAMA Surg 153(9):791-799

Granberg TA, Danielsson N, Fredriksson A, Nordstrom J, Pilemalm S, Tjernstrom R, Mojir KY (2016) Using semi-professionals in emergency response. In: The 16th international conference on information systems for crisis response and management (ISCRAM 2016), May 2016, Rio de Janeiro, Brazil

Granberg TA, Fredriksson A, Pilemalm S, Yousefi Mojir K (2017) Effektivt sambruk av kommunala resurser för ökad säkerhet och trygghet. Linköping University Electronic Press, Linköping

Griffis H, Wu L, Naim M, Bradley R, Tobin J, McNally B, Vellano K, Quan L, Markenson D, Rossano J et al (2020) Characteristics and outcomes of AED use in pediatric cardiac arrest in public settings: the influence of neighborhood characteristics. Resuscitation 146:126-131

Groeneveld PW, Owens DK (2005) Cost-effectiveness of training unselected laypersons in cardiopulmonary resuscitation and defibrillation. Am J Med 118(1):58-67

Groh WJ, Birnbaum A, Barry A, Anton A, Mann NC, Peberdy MA, Vijayaraghavan K, Powell J, Mosesso VN Jr, Investigators PT et al (2007) Characteristics of volunteers responding to emergencies in the public access defibrillation trial. Resuscitation 72(2):193-199

Gross B, Schanderl F, Staedt N, Elsner C (2019) Dispatching first responders via mobile application systems status quo of implementation in Germany, evidence and challenges during introduction. Notfall \& Rettungsmedizin 22(6):483-491

Grunau B, Humphries K, Stenstrom R, Pennington S, Scheuermeyer F, van Diepen S, Awad E, Al Assil R, Kawano T, Brooks S et al (2020) Public access defibrillators: gender-based inequities in access and application. Resuscitation 150:17-22. https://doi.org/10.1016/j.resuscitation.2020.02.024

Gupta S, Chen Y, Zhang Y, Sessions R (2020) Artificially intelligent (AI) drones for first responders. In: AMCIS

Hajari H, Salerno J, Weiss LS, Menegazzi JJ, Karimi H, Salcido DD (2020) Simulating public buses as a mobile platform for deployment of publicly accessible automated external defibrillators. Prehosp Emerg Care 24(2):238-244

Hancock CJ, Delaney PG, Eisner ZJ, Kroner E, Mahamet-Nuur I, Scott JW, Raghavendran K (2020) Developing a lay first responder program in chad: a 12-month follow-up evaluation of a rural prehospital emergency care program. Prehosp Disaster Med 35(5):546-553

Hansen CM, Wissenberg M, Weeke P, Ruwald MH, Lamberts M, Lippert FK, Gislason GH, Nielsen SL, Køber L, Torp-Pedersen C, Folke F (2013) Automated external defibrillators inaccessible to more than half of nearby cardiac arrests in public locations during evening, nighttime, and weekends. Circulation 128(20):2224-2231. https://doi.org/10.1161/CIRCULATIONAHA.113.003066

Hansen CM, Kragholm K, Pearson DA, Tyson C, Monk L, Myers B, Nelson D, Dupre ME, Fosbøl EL, Jollis JG et al (2015a) Association of bystander and first-responder intervention with survival after out-of-hospital cardiac arrest in North Carolina, 2010-2013. JAMA 314(3):255-264

Hansen SM, Brøndum S, Thomas G, Rasmussen SR, Kvist B, Christensen A, Lyng C, Lindberg J, Lauritsen TL, Lippert FK et al (2015b) Home care providers to the rescue: a novel first-responder programme. PLoS ONE 10(10):e0141352

Hartslagnu. https://hartslagnu.nl/. Accessed 18 Oct 2020

Harve H, Silfvast T (2004) The use of automated external defibrillators by non-medical first responders in Finland. Eur J Emerg Med 11(3):130-133 
Haskins B, Smith K, Cameron P, Bernard S, Nehme Z, Murphy-Smith J, Metcalf M, Moussa R, Harvey D, Turnbull L et al (2020) The impact of bystander relation and medical training on out-of-hospital cardiac arrest outcomes. Resuscitation 150:72-79

Hasselqvist-Ax I, Nordberg P, Herlitz J, Svensson L, Jonsson M, Lindqvist J, Ringh M, Claesson A, Björklund J, Andersson JO et al (2017) Dispatch of firefighters and police officers in out-of-hospital cardiac arrest: a nationwide prospective cohort trial using propensity score analysis. J Am Heart Assoc 6(10): 005873

Hasselqvist-Ax I, Nordberg P, Svensson L, Hollenberg J, Joelsson-Alm E (2019) Experiences among firefighters and police officers of responding to out-of-hospital cardiac arrest in a dual dispatch programme in Sweden: an interview study. BMJ Open 9(11):e030895. https://doi.org/10.1136/bmjopen-2019030895

Hatakeyama T, Kiguchi T, Kobayashi D, Nakamura N, Nishiyama C, Hayashida S, Kiyohara K, Kitamura T, Kawamura T, Iwami T (2020) Effectiveness of dispatcher instructions-dependent or independent bystander cardiopulmonary resuscitation on neurological survival among patients with out-of-hospital cardiac arrest. J Cardiol 75(3):315-322

HeartRunner Sweden AB. https://heartrunner.com/. Accessed 18 Oct 2020

Heidari M, Aryankhesal A, Khorasani-Zavareh D (2019) Laypeople roles at road traffic crash scenes: a systematic review. Int J Inj Contr Saf Promot 26(1):82-91

Henriksen FL, Schorling P, Hansen B, Schakow H, Larsen ML (2016) Firstaed emergency dispatch, global positioning of community first responders with distinct roles - a solution to reduce the response times and ensuring an AED to early defibrillation in the rural area Langeland. Int J Networking Virtual Organ 16(1):86-102

Herlitz J, Ekström L, Wennerblom B, Axelsson A, Bång A, Holmberg S (1994) Effect of bystander initiated cardiopulmonary resuscitation on ventricular fibrillation and survival after witnessed cardiac arrest outside hospital. Heart 72(5):408-412

Herlitz J, Bång A, Gunnarsson J, Engdahl J, Karlson B, Lindqvist J, Waagstein L (2003) Factors associated with survival to hospital discharge among patients hospitalised alive after out of hospital cardiac arrest: change in outcome over 20 years in the community of Göteborg, Sweden. Heart 89(1):25-30

Herlitz J, Engdahl J, Svensson L, Ängquist KA, Young M, Holmberg S (2005) Factors associated with an increased chance of survival among patients suffering from an out-of-hospital cardiac arrest in a national perspective in Sweden. Am Heart J 149(1):61-66

Hess EP, White RD (2010) Optimizing survival from out-of-hospital cardiac arrest. J Cardiovasc Electrophysiol 21(5):590-595

Hollenberg J, Riva G, Bohm K, Nordberg P, Larsen R, Herlitz J, Pettersson H, Rosenqvist M, Svensson L (2009) Dual dispatch early defibrillation in out-of-hospital cardiac arrest: the salsa-pilot. Eur Heart J 30(14):1781-1789

Holmberg MJ, Vognsen M, Andersen MS, Donnino MW, Andersen LW (2017) Bystander automated external defibrillator use and clinical outcomes after out-of-hospital cardiac arrest: a systematic review and meta-analysis. Resuscitation 120:77-87

Høyer CB, Christensen EF (2009) Fire fighters as basic life support responders: a study of successful implementation. Scand J Trauma Resuscit Emerg Med 17(1):1-7

Huang CY, Wen TH (2014) Optimal installation locations for automated external defibrillators in Taipei 7-eleven stores: using GIS and a genetic algorithm with a new stirring operator. Computational and mathematical methods in medicine 2014

Husain S, Eisenberg M (2013) Police AED programs: a systematic review and meta-analysis. Resuscitation 84(9):1184-1191

iHelp. https://www.ihelp-world.com/. Accessed 18 Oct 2020

Ingolfsson A (2013) EMS planning and management. In: Operations research and health care policy. Springer, pp 105-128

Jayaraman S, Mabweijano JR, Lipnick MS, Caldwell N, Miyamoto J, Wangoda R, Mijumbi C, Hsia R, Dicker R, Ozgediz D (2009) Current patterns of prehospital trauma care in Kampala, Uganda and the feasibility of a lay-first-responder training program. World J Surg 33(12):2512-2521

Jermyn BD (2000) Cost-effectiveness analysis of a rural/urban first-responder defibrillation program. Prehosp Emerg Care 4(1):43-47

Jonsson M, Berglund E, Djärv T, Nordberg P, Claesson A, Forsberg S, Nord A, Tan HL, Ringh M (2020) A brisk walk-real-life travelling speed of lay responders in out-of-hospital cardiac arrest. Resuscitation 151:197-204 
Jorgenson DB, Skarr T, Russell JK, Snyder DE, Uhrbrock K (2003) Aed use in businesses, public facilities and homes by minimally trained first responders. Resuscitation 59(2):225-233

Kappus RM, McCullough G (2020) The feasibility of a novel method of bystander CPR training: a pilot study. Am J Emerg Med 38(3):594-597

Karam N, Narayanan K, Bougouin W, Benameur N, Beganton F, Jost D, Lamhaut L, Perier MC, Cariou A, Celermajer DS et al (2017) Major regional differences in automated external defibrillator placement and basic life support training in France: further needs for coordinated implementation. Resuscitation 118:49-54

Karlsson L, Hansen CM, Wissenberg M, Hansen SM, Lippert FK, Rajan S, Kragholm K, Møller SG, Søndergaard KB, Gislason GH, Torp-Pedersen C, Folke F (2019) Automated external defibrillator accessibility is crucial for bystander defibrillation and survival: a registry-based study. Resuscitation 136:30-37

Kartawijaya T, Townsend E, Tully K, Isihara P, Diedrichs DR, Flores G, Shi C, Ward J (2019) Is now the time to invest in emergency smart-navigated multiple-response quadcopter fleets? J Unmanned Veh Syst 7(2): 145-155

Kash BA, Spaulding A, Johnson CE, Gamm L (2014) Success factors for strategic change initiatives: a qualitative study of healthcare administrators' perspectives. J Healthc Manag 59(1):65-81

KATRETTER. https://katretter.de/. Accessed 18 Oct 2020

Kay BJ, Myrick JA (1982) An evaluation of program implementation strategies for a rural first-responder system. J Community Health 8(2):57-68

Khan MNH, Neustaedter C (2019) An exploratory study of the use of drones for assisting firefighters during emergency situations. In: Proceedings of the 2019 CHI conference on human factors in computing systems, pp 1-14

Kim DK, Shin SD, Ro YS, Song KJ, Hong KJ, Joyce Kong SY (2020) Place-provider-matrix of bystander cardiopulmonary resuscitation and outcomes of out-of-hospital cardiac arrest: a nationwide observational cross-sectional analysis. PLoS ONE 15(5):e0232999

Kitamura T, Iwami T, Kawamura T, Nagao K, Tanaka H, Hiraide A (2010) Nationwide public-access defibrillation in Japan. New Engl J Med 362(11):994-1004. https://doi.org/10.1056/NEJMoa0906644

Kiyohara K, Kitamura T, Sakai T, Nishiyama C, Nishiuchi T, Hayashi Y, Sakamoto T, Marukawa S, Iwami T (2016) Public-access AED pad application and outcomes for out-of-hospital cardiac arrests in Osaka, Japan. Resuscitation 106:70-75

Kobayashi D, Sado J, Kiyohara K, Kitamura T, Kiguchi T, Nishiyama C, Okabayashi S, Shimamoto T, Matsuyama T, Kawamura T, Iwami T (2020) Public location and survival from out-of-hospital cardiac arrest in the public-access defibrillation era in Japan. J Cardiol 75(1):97-104. https://doi.org/10.1016/ j.jjcc.2019.06.005

Konert A, Smereka J, Szarpak L (2019) The use of drones in emergency medicine: practical and legal aspects. Emerg Med Int 2019:5. https://doi.org/10.1155/2019/3589792

Kooij FO, van Alem AP, Koster RW, de Vos R (2004) Training of police officers as first responders with an automated external defibrillator. Resuscitation 63(1):33-41

Krammel M, Lobmeyr E, Sulzgruber P, Winnisch M, Weidenauer D, Poppe M, Datler P, Zeiner S, Keferboeck M, Eichelter J et al (2020) The impact of a high-quality basic life support police-based first responder system on outcome after out-of-hospital cardiac arrest. PLoS ONE 15(6):e0233966

Krey M (2018) Drones in healthcare: application in Swiss hospitals. In: 51st Hawaii international conference on system sciences, Waikoloa, HI. https://scholarspace.manoa.hawaii.edu/bitstream/10125/50277/1/ paper0390.pdf

Kua PHJ, White AE, Ng WY, Fook-Chong S, Ng EKX, Ng YY, Ong MEH (2018) Knowledge and attitudes of Singapore schoolchildren learning cardiopulmonary resuscitation and automated external defibrillator skills. Singapore Med J 59(9):487

Lamote I, Calle P, Lyphout C, Van de Voorde P (2020) Adequacy of bystander actions in unconscious patients: an audit study in the Ghent region (Belgium). Eur J Emerg Med 27(2):105-109

LandIRettung. https://land-rettung.de/. Accessed 18 Oct 2020

Latimer AJ, McCoy AM, Sayre MR (2018) Emerging and future technologies in out-of-hospital cardiac arrest care. Cardiol Clin 36(3):429-441

Latuska KM, Graf RL, Zwislewski A, Meyer LK, Nanassy AD et al (2019) Stop the bleed training improves knowledge, skills, and confidence among school nurses. J Contin Educ Nurs 50(11):501-507

Lee CT, Lee YC, Chen AY (2019) In-building automated external defibrillator location planning and assessment through building information models. Autom Constr 106:102883 
Lei R, Swartz MD, Harvin JA, Cotton BA, Holcomb JB, Wade CE, Adams SD (2019) Stop the bleed training empowers learners to act to prevent unnecessary hemorrhagic death. Am J Surg 217(2):368-372

Lerner EB, Billittier AJ IV, Moscati RM, Adolf JE (2003a) The time first-response fire fighters have to initiate care in a midsize city. J Emerg Med 25(2):171-174

Lerner EB, Hinchey PR, Billittier AJ (2003b) A survey of first-responder firefighters' attitude, opinions, and concerns about their automated external defibrillator program. Prehosp Emerg Care 7(1):120-124

Levy MJ, Seaman KG, Millin MG, Bissell RA, Jenkins JL (2013) A poor association between out-of-hospital cardiac arrest location and public automated external defibrillator placement. Prehosp Disaster Med 28(4):342-7

Lichtenhahn A, Kruse M, Büsing J, Vogel M, Konrad C (2019) Analysis of a first responder system for emergency medical care in rural areas: first results and experiences. Anaesthesist 68(9):618-625

Lin BC, Chen CW, Chen CC, Kuo CL, Ic F, Ho CK, Liu IC, Chan TC (2016) Spatial decision on allocating automated external defibrillators (AED) in communities by multi-criterion two-step floating catchment area (MC2SFCA). Int J Health Geogr 15(1):1-14

Lorenzo G, Maria Antonia B, Piero Maria B, Andrea P, Guido Francesco V, Enrico Gianluca C (2020) Development of a novel framework to propose new strategies for automated external defibrillators deployment targeting residential out-of-hospital cardiac arrests: application to the city of Milan. ISPRS Int J Geo-Inf. https://doi.org/10.3390/ijgi9080491

Lowndes B, Law K, Abdelrahman A, Prytz E, Jonson CO, Sztajnkrycer M, Hawthorne H, Franz W, Blocker R, Hallbeck MS (2019) Preliminary investigation of civilian clinician perspectives \& just-in-time guidance for tourniquet use to "Stop the bleed". Milit Med 184(Suppl 1):28-36

Lukumay GG, Outwater AH, Mkoka DA, Ndile ML, Saveman BI (2019) Traffic police officers' experience of post-crash care to road traffic injury victims: a qualitative study in Tanzania. BMC Emerg Med 19(1):1-11

Mackle C, Bond R, Torney H, Mcbride R, Mclaughlin J, Finlay D, Biglarbeigi P, Brisk R, Harvey A, Mceneaney D (2020) A data-driven simulator for the strategic positioning of aerial ambulance drones reaching out-of-hospital cardiac arrests: a genetic algorithmic approach. IEEE J Transl Eng Health Med 8:1-10. https://doi.org/10.1109/JTEHM.2020.2987008

Maisch S, Friederich P, Goetz A (2006) Public access defibrillation: Beschränkungen des einsatzes durch ausgebildete ersthelfer und laien. Anaesthesist 55(12):1281-1290

Mandell MB, Becker LR (1996) A model for locating automatic external defibrillators. Socioecon Plann Sci 30(1):51-66

Mao R, Du B, Sun D, Kong N (2019) Optimizing a UAV-based emergency medical service network for trauma injury patients. In: 2019 IEEE 15th international conference on automation science and engineering (CASE), IEEE, pp 721-726

Elena Nenni M, Stefano Riemma VDPSM (2020) Development of a drone-supported emergency medical service. Int J Technol 11(4):656-666. https://doi.org/10.14716/ijtech.v11i4.3951

Mark DB, Hansen SM, Starks ML, Cummings ML (2017) Drone-based automatic external defibrillators for sudden death? Do we need more courage or more serenity?

Mateen FJ, Leung KHB, Vogel AC, Cissé AF, Chan TCY (2020) A drone delivery network for antiepileptic drugs: a framework and modelling case study in a low-income country. Trans R Soc Trop Med Hygiene 114(4):308-314. https://doi.org/10.1093/trstmh/trz131

Matinrad N (2019) An operations research approach for daily emergency management. Linköping University Electronic Press. Licentiate thesis

Matinrad N, Granberg TA, Ennab Vogel N, Angelakis V (2019) Optimal dispatch of volunteers to out-ofhospital cardiac arrest patients. In: Proceedings of the 52nd Hawaii international conference on system sciences

Matt C, Hess T, Benlian A (2015) Digital transformation strategies. Bus Inf Syst Eng 57(5):339-343

McCarty JC, Caterson EJ, Chaudhary MA, Herrera-Escobar JP, Hashmi ZG, Goldberg SA, Goolsby C, Lipsitz S, Haider AH, Goralnick E (2019a) Can they stop the bleed? Evaluation of tourniquet application by individuals with varying levels of prior self-reported training. Injury 50(1):10-15

McCarty JC, Hashmi ZG, Herrera-Escobar JP, de Jager E, Chaudhary MA, Lipsitz SR, Jarman M, Caterson EJ, Goralnick E (2019b) Effectiveness of the American college of surgeons bleeding control basic training among laypeople applying different tourniquet types: a randomized clinical trial. JAMA Surg 154(10):923-929

Meine Stadt Rettet. https://www.meine-stadt-rettet.de/. Accessed 18 Oct 2020 
Mell HK, Sayre MR (2008) Public access defibrillators and fire extinguishers: are comparisons reasonable? Progr Cardiovasc Dis 51(3):204-212

Mermiri MI, Mavrovounis GA, Pantazopoulos IN (2020) Drones for automated external defibrillator delivery: Where do we stand? J Emerg Med 59(5):660-667. https://doi.org/10.1016/j.jemermed.2020.07. 027

Merriam-Webster. Merriam-Webster dictionary. https://www.merriam-webster.com/dictionary/layman. Accessed 24 June 2020

Mobile Retter. https://www.mobile-retter.org/. Accessed 18 Oct 2020

MobileLebensretter. https://www.mobile-lebensretter.de/. Accessed 18 Oct 2020

Moon S, Vadeboncoeur TF, Kortuem W, Kisakye M, Karamooz M, White B, Brazil P, Spaite DW, Bobrow BJ (2015) Analysis of out-of-hospital cardiac arrest location and public access defibrillator placement in metropolitan Phoenix, Arizona. Resuscitation 89:43-49. https://doi.org/10.1016/j.resuscitation.2014. 10.029

Moore MJ, Hamilton AJ, Cairns KJ, Marshall A, Glover BM, McCann CJ, Jordan J, Kee F, Adgey AAJ (2008) The northern Ireland public access defibrillation (NIPAD) study: effectiveness in urban and rural populations. Heart 94(12):1614-1619

Moran PS, Teljeur C, Masterson S, O’Neill M, Harrington P, Ryan M (2015) Cost-effectiveness of a national public access defibrillation programme. Resuscitation 91:48-55. https://doi.org/10.1016/j. resuscitation.2015.03.017

Morgan DP, Muscatello D, Hayen A, Travaglia J (2019) Human factors influencing out-of-hospital cardiac arrest survival. Emerg Med Australas 31(4):600-604

Moriwaki K, Watanabe T, Yasuda M, Katagiri T, Ueki M, Kurita S, Sanuki M, Tsutsumi YM (2020) An outcome study of adult in-hospital cardiac arrests in non-monitored areas with resuscitation attempted using AED. Am J Emerg Med 38(12):2524-2530. https://doi.org/10.1016/j.ajem.2019.12.025

Murad MK, Husum H (2010) Trained lay first responders reduce trauma mortality: a controlled study of rural trauma in Iraq. Prehosp Disaster Med 25(6):533-539

Murakami Y, Iwami T, Kitamura T, Nishiyama C, Nishiuchi T, Hayashi Y, Kawamura T, null null (2014) Outcomes of out of hospital cardiac arrest by public location in the public access defibrillation era. J Am Heart Assoc 3(2):e000533

MV SCHOCKT App. https://www.mv-schockt.de/start/. Accessed 18 Oct 2020

Myerburg RJ, Fenster J, Velez M, Rosenberg D, Lai S, Kurlansky P, Newton S, Knox M, Castellanos A (2002) Impact of community-wide police car deployment of automated external defibrillators on survival from out-of-hospital cardiac arrest. Circulation 106(9):1058-1064

Myers DC, Mohite M (2009) Locating automated external defibrillators in a university community. J Oper Res Soc 60(6):869-872

myResponder. https://www.scdf.gov.sg/home/community-volunteers/mobile-applications. Accessed 25 May 2021

Myrick JA, Kay BJ, Kishbaugh D, Pittman JV, Sayford NF (1983) Acceptance of a volunteer first-responder system in rural communities: a field experiment. Med Care 21(4):389-399

Nanassy AD, Graf RL, Budziszewski R, Thompson R, Zwislewski A, Meyer L, Grewal H (2020) Stop the bleed: The impact of a basic bleeding control course on high school personnel's perceptions of self-efficacy and school preparedness. Workplace Health \& Safety 68(12):552-559

Narikawa K, Sakamoto T, Kubota K, Suzukawa M, Yonekawa C, Yamashita K, Toyokuni Y, Yasuda Y, Kobayashi A, Iijima K (2014) Predictability of the call triage protocol to detect if dispatchers should activate community first responders. Prehosp Disaster Med 29(5):484

Nas J, Thannhauser J, Herrmann J, van der Wulp K, van Grunsven P, van Royen N, de Boer M, Bonnes J, Brouwer M (2018) Changes in automated external defibrillator use and survival after out-of-hospital cardiac arrest in the Nijmegen area. Neth Hear J 26(12):600-605

Naths G, Juergens C, Peter A (2007) "medical first responder" as a supplement to rescue services: efficiency of non-professional emergency support units. Notfall Rettungsmedizin 10(5):350-356

Nehme Z, Andrew E, Bernard S, Haskins B, Smith K (2019) Trends in survival from out-of-hospital cardiac arrests defibrillated by paramedics, first responders and bystanders. Resuscitation 143:85-91

Nelson RD, Bozeman W, Collins G, Booe B, Baker T, Alson R (2015) Mobile versus fixed deployment of automated external defibrillators in rural EMS. Prehosp Disaster Med 30(2):152-154. https://doi.org/ $10.1017 /$ S1049023X1500014X 
Nichol G, Hallstrom AP, Ornato JP, Riegel B, Stiell IG, Valenzuela T, Wells GA, White RD, Weisfeldt ML (1998) Potential cost-effectiveness of public access defibrillation in the United States. Circulation 97(13):1315-1320

Nielsen AM, Folke F, Lippert FK, Rasmussen LS (2013) Use and benefits of public access defibrillation in a nation-wide network. Resuscitation 84(4):430-434

Nikbakhsh E, Farahani RZ (2011) Humanitarian logistics planning in disaster relief operations. Logistics operations and management: Concepts and models 291

Nilsson A, Åslund K, Lampi M, Nilsson H, Jonson CO (2015) Improved and sustained triage skills in firemen after a short training intervention. Scand J Trauma Resuscit Emerg Med 23(1):1-6

Nord A (2017) Bystander CPR: new aspects of CPR training among students and the importance of bystander education level on survival. Linköping University Electronic Press. PhD thesis

Nordberg P, Hollenberg J, Rosenqvist M, Herlitz J, Jonsson M, Järnbert-Petterson H, Forsberg S, Dahlqvist T, Ringh M, Svensson L (2014) The implementation of a dual dispatch system in out-of-hospital cardiac arrest is associated with improved short and long term survival. Eur Heart $\mathbf{J}$ Acute Cardiovasc Care 3(4):293-303

Nordberg P, Jonsson M, Forsberg S, Ringh M, Fredman D, Riva G, Hasselqvist-Ax I, Hollenberg J (2015) The survival benefit of dual dispatch of ems and fire-fighters in out-of-hospital cardiac arrest may differ depending on population density - a prospective cohort study. Resuscitation 90:143-149

Ohta S, Harikae K, Sekine K, Nemoto M (2014) How, when, and where have rental automated external defibrillators been used in Japan? J Cardiol 64(2):117-120

Otto A, Agatz N, Campbell J, Golden B, Pesch E (2018) Optimization approaches for civil applications of unmanned aerial vehicles (UAVs) or aerial drones: a survey. Networks 72(4):411-458

Oving I, Masterson S, Tjelmeland IB, Jonsson M, Semeraro F, Ringh M, Truhlar A, Cimpoesu D, Folke F, Beesems SG et al (2019) First-response treatment after out-of-hospital cardiac arrest: a survey of current practices across 29 countries in Europe. Scand J Trauma Resuscit Emerg Med 27(1):112

Park SK, Uhm TH (2020) How many automatic external defibrillators do South Korean golf courses need? J Distrib Sci 18(4):73-78

Pferzinger M, Rammerstorfer P (2017) Design thinking based digital transformation in healthcare. In: Digitale Transformation von Dienstleistungen im Gesundheitswesen II, Springer, pp 13-22

Phung VH, Trueman I, Togher F, Orner R, Siriwardena AN (2017) Community first responders and responder schemes in the United Kingdom: systematic scoping review. Scand J Trauma Resuscit Emerg Med 25(1):58

Phung VH, Trueman I, Togher F, Ørner R, Siriwardena AN (2018) Perceptions and experiences of community first responders on their role and relationships: qualitative interview study. Scand J Trauma Resuscit Emerg Med 26(1):13

Pijls RW, Nelemans PJ, Rahel BM, Gorgels AP (2016) A text message alert system for trained volunteers improves out-of-hospital cardiac arrest survival. Resuscitation 105:182-187

Pijls RW, Nelemans PJ, Rahel BM, Gorgels AP (2019) Characteristics of a novel citizen rescue system for out-of-hospital cardiac arrest in the Dutch province of Limburg: relation to incidence and survival. Neth Hear J 27(2):100-107

Portela RC, Taylor SE, Sherrill CS, Dowlen WS, March J, Kitch B, Brewer K (2020) Application of different commercial tourniquets by laypersons: would public-access tourniquets work without training? Acad Emerg Med 27(4):276-282

Portner M, Pollack M, Schirk S, Schlenker M (2004) Out-of-hospital cardiac arrest locations in a rural community: Where should we place AEDs? Prehospital Disaster Med 19:352-5 (discussion 355)

Pozner CN, Zane R, Nelson SJ, Levine M (2004) International ems systems: the United States: past, present, and future. Resuscitation 60(3):239-244

Pulse Point App. https://www.pulsepoint.org/. Accessed 18 Oct 2020

Pulver A, Wei R (2018) Optimizing the spatial location of medical drones. Appl Geogr 90:9-16

Pulver A, Wei R, Mann C (2016) Locating AED enabled medical drones to enhance cardiac arrest response times. Prehosp Emerg Care 20(3):378-389

Quarantelli EL (1995) Disasters are different, therefore planning for and managing them requires innovative as well as traditional behaviors

Quinn L, Challen K, Walter D (2009) Medical and prehospital care training in UK fire and rescue services. Emerg Med J 26(8):601-603

Qutub MA (2019) Assessment of awareness and attitudes regarding automated external defibrillators (AED) in sports facilities in Jeddah, Saudi Arabia. Int J Pharmaceut Res Allied Sci 8(4):105-110 
Ramsell E, Pilemalm S, Andersson Granberg T (2017) Using volunteers for emergency response in rural areas: network collaboration factors and it support in the case of enhanced neighbors. In: The 14th international conference on information systems for crisis response and management, May 21-24, Albi, Occitanie Pyrénées-Méditerranée, France, ISCRAM Association, vol 14, pp 985-995

Ramsell E, Andersson Granberg T, Pilemalm S (2019). Identifying functions for smartphone basedapplications in volunteer emergency response. In: 16th international conference on information systems for crisis response and management, Valencia (Spain), May 19-22, 2019, Information Systems for Crisis Response and Management, pp 1044-1056

Rao G, Mago V, Savage DW, Beyer R (2019) Identifying and allocating resources during out of hospital cardiac arrest. In: 2019 international conference on internet of things (iThings) and IEEE green computing and communications (GreenCom) and IEEE cyber, physical and social computing (CPSCom) and IEEE smart data (SmartData), IEEE, pp 959-966

Rao G, Choudhury S, Lingras P, Savage D, Mago V (2020) Surf: identifying and allocating resources during out-of-hospital cardiac arrest. BMC Med Inform Decis Mak 20(11):1-15

Raun L, Pederson J, Campos L, Ensor K, Persse D (2019) Effectiveness of the dual dispatch to cardiac arrest policy in Houston, Texas. J Public Health Manag Pract 25(5):E13-E21

Rauner MS, Bajmoczy N (2003) How many AEDs in which region? An economic decision model for the Austrian red cross. Eur J Oper Res 150(1):3-18

Rea T, Blackwood J, Damon S, Phelps R, Eisenberg M (2011) A link between emergency dispatch and public access AEDs: potential implications for early defibrillation. Resuscitation 82(8):995-998

Rea TD, Olsufka M, Bemis B, White L, Yin L, Becker L, Copass M, Eisenberg M, Cobb L (2010) A population-based investigation of public access defibrillation: role of emergency medical services care. Resuscitation 81(2):163-167

Red Cross First Aid App Australia. https://www.redcross.org.au/get-involved/learn/first-aid/first-aid-app. Accessed 18 Oct 2020

Region Östergötland. https://vardgivarwebb.regionostergotland.se/Startsida/Verksamheter/Narsjukvardeni-centrala-Ostergotland/enheten_for_prehospital_vard/Ambulanssjukvardens-organisation21/. Accessed 28 June 2020

Reuter-Oppermann M, van den Berg PL, Vile JL (2017) Logistics for emergency medical service systems. Health Syst 6(3):187-208

Ringh M, Fredman D, Nordberg P, Stark T, Hollenberg J (2011) Mobile phone technology identifies and recruits trained citizens to perform $\mathrm{CPR}$ on out-of-hospital cardiac arrest victims prior to ambulance arrival. Resuscitation 82(12):1514-1518

Ringh M, Rosenqvist M, Hollenberg J, Jonsson M, Fredman D, Nordberg P, Järnbert-Pettersson H, Hasselqvist-Ax I, Riva G, Svensson L (2015) Mobile-phone dispatch of laypersons for CPR in outof-hospital cardiac arrest. N Engl J Med 372(24):2316-2325

Ringh M, Hollenberg J, Palsgaard-Moeller T, Svensson L, Rosenqvist M, Lippert FK, Wissenberg M, Malta Hansen C, Claesson A, Viereck S, Zijlstra JA, Koster RW, Herlitz J, Blom MT, Kramer-Johansen J, Tan HL, Beesems SG, Hulleman M, Olasveengen TM, Folke F, for the COSTA study group (research collaboration between Copenhagen, Oslo, STockholm, and Amsterdam) (2018) The challenges and possibilities of public access defibrillation. J Internal Med 283(3):238-256

Riva G, Jonsson M, Ringh M, Claesson A, Djärv T, Forsberg S, Nordberg P, Rubertsson S, Rawshani A, Nord A et al (2020) Survival after dispatcher-assisted cardiopulmonary resuscitation in out-of-hospital cardiac arrest. Resuscitation 157:195-201. https://doi.org/10.1016/j.resuscitation.2020.08.125

Roberts A, Nimegeer A, Farmer J, Heaney DJ (2014) The experience of community first responders in co-producing rural health care: in the liminal gap between citizen and professional. BMC Health Serv Res 14(1):1-10

Roccia WD, Modic PE, Cuddy MA (2003) Automated external defibrillator use among the general population. J Dent Educ 67(12):1355-1361

Rørtveit S, Meland E (2010) First responder resuscitation teams in a rural Norwegian community: sustainability and self-reports of meaningfulness, stress and mastering. Scand J Trauma Resuscit Emerg Med 18(1):1-6

Ross EM, Mapp JG, Redman TT, Brown DJ, Kharod CU, Wampler DA (2018) The tourniquet gap: a pilot study of the intuitive placement of three tourniquet types by laypersons. J Emerg Med 54(3):307-314

Ross P, Nolan J, Hill E, Dawson J, Whimster F, Skinner D (2001a) The use of AEDs by police officers in the city of London. Resuscitation 50(2):141-146 
Ross P, Nolan J, Hill E, Dawson J, Whimster F, Skinner D (2001b) The use of AEDs by police officers in the city of London. Resuscitation 50(2):141-146

Sakai T, Iwami T, Kitamura T, Nishiyama C, Kawamura T, Kajino K, Tanaka H, Marukawa S, Tasaki O, Shiozaki T, Ogura H, Kuwagata Y, Shimazu T (2011) Effectiveness of the new "mobile AED map" to find and retrieve an AED: a randomised controlled trial. Resuscitation 82(1):69-73

Samani H, Zhu R (2016) Robotic automated external defibrillator ambulance for emergency medical service in smart cities. IEEE Access 4:268-283

Saner H, Morger C, Eser P, von Planta M (2013) Dual dispatch early defibrillation in out-of-hospital cardiac arrest in a mixed urban-rural population. Resuscitation 84(9):1197-1202

Sanfridsson J, Sparrevik J, Hollenberg J, Nordberg P, Djärv T, Ringh M, Svensson L, Forsberg S, Nord A, Andersson-Hagiwara $\mathrm{M}$ et al (2019) Drone delivery of an automated external defibrillator-a mixed method simulation study of bystander experience. Scand J Trauma Resuscit Emerg Med 27(1):40

Sarkisian L, Mickley H, Schakow H, Gerke O, Jørgensen G, Larsen ML, Henriksen FL (2020) Global positioning system alerted volunteer first responders arrive before emergency medical services in more than four out of five emergency calls. Resuscitation 152:170-176

Schmidt-Polończyk N, Jaskula J (2020) Assessment of knowledge of Polish University technical students on using an automated external defibrillator (AED) — survey results. Saf. Fire Technol. 56:62-75. https:// doi.org/10.12845/sft.56.2.2020.4

Schober P, van Dehn FB, Bierens JJ, Loer SA, Schwarte LA (2011) Public access defibrillation: time to access the public. Ann Emerg Med 58(3):240-247

Scholten AC, van Manen JG, van der Worp WE, IJzerman MJ, Doggen CJ (2011) Early cardiopulmonary resuscitation and use of automated external defibrillators by laypersons in out-of-hospital cardiac arrest using an SMS alert service. Resuscitation 82(10):1273-1278

Schwartz DG, Ataiants J, Roth A, Marcu G, Yahav I, Cocchiaro B, Khalemsky M, Lankenau S (2020) Layperson reversal of opioid overdose supported by smartphone alert: a prospective observational cohort study. EClinical Med 25:100474

Scott G, Olola C, Gardett MI, Ashwood D, Broadbent M, Sangaraju S, Stiegler P, Fivaz MC, Clawson JJ (2020) Ability of layperson callers to apply a tourniquet following protocol-based instructions from an emergency medical dispatcher. Prehosp Emerg Care 24(6):831-838

Scott J, Scott C (2017) Drone delivery models for healthcare. In: Proceedings of the 50th Hawaii international conference on system sciences

Scott JE, Scott CH (2020) Drone delivery models for medical emergencies. Springer, Cham, pp 69-85

Scquizzato T, Burkart R, Greif R, Monsieurs KG, Ristagno G, Scapigliati A, Semeraro F (2020) Mobile phone systems to alert citizens as first responders and to locate automated external defibrillators: a European survey. Resuscitation 151:39-42

Sedig K, Seaton M, Drennan I, Cheskes S, Dainty K (2020) "Drones are a great idea! what is an AED?" Novel insights from a qualitative study on public perception of using drones to deliver automatic external defibrillators. Resuscitation Plus 4:100033. https://doi.org/10.1016/j.resplu.2020.100033

Seguin C, Blaquière G, Loundou A, Michelet P, Markarian T (2018) Unmanned aerial vehicles (drones) to prevent drowning. Resuscitation 127:63-67

Sharieff W, Kaulback K (2007) Assessing automated external defibrillators in preventing deaths from sudden cardiac arrest: an economic evaluation. Int J Technol Assess Health Care 23(3):362

Shimamoto T, Kiyohara K, Matsuyama T, Kitamura T, Kiguchi T, Nishiyama C, Kobayashi D, Okabayashi S, Kawamura T, Iwami T (2020) Impact of bystander cardiopulmonary resuscitation and dispatcher assistance on survival after out-of-hospital cardiac arrest among adult patients by location of arrest. Int Heart J 61(1):46-53

Shirane T (2020) A systematic review of effectiveness of automated external defibrillators delivered by drones. Global J Health Sci 12(12):101-111

Shuster M, Keller JL (1993) Effect of fire department first-responder automated defibrillation. Ann Emerg Med 22(4):721-727

Siddiq AA, Brooks SC, Chan TC (2013) Modeling the impact of public access defibrillator range on public location cardiac arrest coverage. Resuscitation 84(7):904-909

Increasing cardiac arrest survival by improving the volunteer alerting algorithm. Master's thesis, University of Twente

Smith CM, Colquhoun MC, Samuels M, Hodson M, Mitchell S, O’Sullivan J (2017a) New signs to encourage the use of automated external defibrillators by the lay public. Resuscitation 114:100-105 
Smith CM, Lim Choi Keung SN, Khan MO, Arvanitis TN, Fothergill R, Hartley-Sharpe C, Wilson MH, Perkins GD (2017b) Barriers and facilitators to public access defibrillation in out-of-hospital cardiac arrest: a systematic review. Eur Heart J Qual Care Clin Outcomes 3(4):264-273

Smith CM, Wilson MH, Ghorbangholi A, Hartley-Sharpe C, Gwinnutt C, Dicker B, Perkins GD (2017c) The use of trained volunteers in the response to out-of-hospital cardiac arrest-the Goodsam experience. Resuscitation 121:123-126

Smith K, Rich D, Pinol JP, Hankin J, McNeil J (2001) Acceptance of a medical first-responder role by fire fighters. Resuscitation 51(1):33-38

Sms-livräddare. https://www.smslivraddare.se/. Accessed 06 July 2020

Sondergaard KB, Hansen SM, Pallisgaard JL, Gerds TA, Wissenberg M, Karlsson L, Lippert FK, Gislason GH, Torp-Pedersen C, Folke F (2018) Out-of-hospital cardiac arrest: probability of bystander defibrillation relative to distance to nearest automated external defibrillator. Resuscitation 124:138-144

St John First Aid Apps Australia. https:/www.stjohnsa.com.au/how-we-help/public-access-resources/ first-aid-apps. Accessed 18 Oct 2020

St John First Responder App Western Australia. https://stjohnwa.com.au/online-resources/st-john-firstresponder-app. Accessed 18 Oct 2020

St John Save a Live AED Search and Register App. https://stjohn.ab.ca/savealife/. Accessed 18 Oct 2020

Stadeli KM, Abdullahi D, Ali A, Conrick KM, Paulsen M, Bulger EM, Vavilala MS, Mohamed FB, Ali A, Ibrahim A (2020) Working toward equity in emergencies (we) through stop the bleed: a pilot collaborative health program with the Somali community in Seattle. Am. J. Surg. 219(5):756-763

Stein P, Spahn GH, Müller S, Zollinger A, Baulig W, Brüesch M, Seifert B, Spahn DR (2017) Impact of city police layperson education and equipment with automatic external defibrillators on patient outcome after out of hospital cardiac arrest. Resuscitation 118:27-34

Stenberg R, Pilemalm S, Yousefi Mojir K (2014) Samverkansformer för räddning och respons: Exempel och förslag. Linköping University Electronic Press

Stieglis R, Zijlstra JA, Riedijk F, Smeekes M, van der Worp WE, Koster RW (2020) Aed and text message responders density in residential areas for rapid response in out-of-hospital cardiac arrest. Resuscitation 150:170-177. https://doi.org/10.1016/j.resuscitation.2020.01.031

Stroop R, Kerner T, Strickmann B, Hensel M (2020) Mobile phone-based alerting of CPR-trained volunteers simultaneously with the ambulance can reduce the resuscitation-free interval and improve outcome after out-of-hospital cardiac arrest: a German, population-based cohort study. Resuscitation 147:57-64

Ströhle M, Paal P, Strapazzon G, Avancini G, Procter E, Brugger H (2014) Defibrillation in rural areas. Am J Emerg Med 32(11):1408-1412

Sun CL, Demirtas D, Brooks SC, Morrison LJ, Chan TC (2016) Overcoming spatial and temporal barriers to public access defibrillators via optimization. J Am College Cardiol 68(8):836-845

Sun CL, Brooks SC, Morrison LJ, Chan TC (2017) Ranking businesses and municipal locations by spatiotemporal cardiac arrest risk to guide public defibrillator placement. Circulation 135(12):1104-1119

Sun CL, Karlsson L, Torp-Pedersen C, Morrison LJ, Folke F, Chan TC (2018) Spatiotemporal aed optimization is generalizable. Resuscitation 131:101-107

Sun JH, Wallis LA (2012) The emergency first aid responder system model: using community members to assist life-threatening emergencies in violent, developing areas of need. Emerg Med J 29(8):673-678

Sund B, Svensson L, Rosenqvist M, Hollenberg J (2012) Favourable cost-benefit in an early defibrillation programme using dual dispatch of ambulance and fire services in out-of-hospital cardiac arrest. Eur J Health Econ 13(6):811-818

Svensson A, Elmqvist C, Fridlund B, Rask M, Andersson R, Stening K (2020) Using firefighters as medical first responders to shorten response time in rural areas in Sweden. Aust J Rural Health 28(1):6-14

Tamminen JI, Hoppu SE, Kämäräinen AJ (2019) Professional firefighter and trained volunteer firstresponding units in emergency medical service. Acta Anaesthesiol Scand 63(1):111-116

Tatebe L, Speedy S, Kang D, Barnum T, Cosey-Gay F, Regan S, Stone L, Swaroop M (2019) Empowering bystanders to intervene: trauma responders unify to empower (true) communities. J Surg Res 238:255264

Tay PJM, Pek PP, Fan Q, Ng YY, Leong BSH, Gan HN, Mao DR, Chia MYC, Cheah SO, Doctor N et al (2020) Effectiveness of a community based out-of-hospital cardiac arrest (OHCA) interventional bundle: results of a pilot study. Resuscitation 146:220-228

Thiels CA, Aho JM, Zietlow SP, Jenkins DH (2015) Use of unmanned aerial vehicles for medical product transport. Air Med J 34(2):104-108 
Tierney NJ, Reinhold H, Mira A, Weiser M, Burkart R, Benvenuti C, Auricchio A (2018) Novel relocation methods for automatic external defibrillator improve out-of-hospital cardiac arrest coverage under limited resources. Resuscitation 125:83-89

Toresdahl BG, Harmon KG, Drezner JA (2013) High school automated external defibrillator programs as markers of emergency preparedness for sudden cardiac arrest. J Athl Train 48(2):242-247

Toyokuni Y, Suzukawa M, Yamashita K, Yonekawa C, Kubota K, Yasuda Y, Kobayashi A, Matsubara H (2013) Introduction of the community first responder system into Japan: is that possible? Int J Emerg Med 6(1):34

TrygFonden Hjertestarter. https://hjertestarter.dk/hjerteloeber/bliv-hjerteloeber. Accessed 18 Oct 2020

Tsai YS, Ko PCI, Huang CY, Wen TH (2012) Optimizing locations for the installation of automated external defibrillators (AEDs) in urban public streets through the use of spatial and temporal weighting schemes. Appl Geogr 35(1):394-404

Uppal N, Gondi S (2019) Addressing the ems workforce shortage: how medical students can help bridge the gap. J Emerg Manag (Weston, Mass) 17(5):380-384

Valenzuela TD, Roe DJ, Nichol G, Clark LL, Spaite DW, Hardman RG (2000) Outcomes of rapid defibrillation by security officers after cardiac arrest in casinos. N Engl J Med 343(17):1206-1209

van Alem AP, Vrenken RH, de Vos R, Tijssen JGP, Koster RW (2003) Use of automated external defibrillator by first responders in out of hospital cardiac arrest: prospective controlled trial. BMJ 327(7427):1312

Van de Voorde P, Gautama S, Momont A, Ionescu CM, De Paepe P, Fraeyman N (2017) The drone ambulance [a-uas]: golden bullet or just a blank? Resuscitation 116:46-48

Walia SS, Somarathna K, Hendricks R, Jackson A, Nagarur N (2018) Optimizing the emergency delivery of medical supplies with unmanned aircraft vehicles. In: Barker K, Berry CRD (eds) Proceedings of the 2018 IISE annual conference

Wang K, Liang Y, Zhao L (2017) Multi-stage emergency medicine logistics system optimization based on survival probability. Front Eng Manag 4(2):221-228

Wang TH, Wu HW, Hou PC, Tseng HJ (2019) The utilization of automated external defibrillators in Taiwan. J Formos Med Assoc 118(1:Part 1):148-151

Wankmüller C, Truden C, Korzen C, Hungerländer P, Kolesnik E, Reiner G (2020) Optimal allocation of defibrillator drones in mountainous regions. OR Spectrum 42:785-814, https://epub.wu.ac.at/7715/, open access funding provided by University of Klagenfurt. This work was supported by the European Union Fund for regional development and Interreg V-A Italy Austria 2014-2020 and was carried out, while the first author was employed within the Interreg project START (Smart test of Alpine rescue technology)

Weinholt $\AA$ (2015)Exploring collaboration between the fire and rescue service and new actors: costefficiency and adaptation. Licentiate thesis, Linköping University Electronic Press

White MJ, Loccoh EC, Goble MM, Yu S, Duquette D, Davis MM, Odetola FO, Russell MW (2016) Availability of automated external defibrillators in public high schools. J Pediatr 172:142-146.e1

White RD, Hankins DG, Bugliosi TF (1998) Seven years' experience with early defibrillation by police and paramedics in an emergency medical services system. Resuscitation 39(3):145-151

Winship C, Boyle M, Williams B (2014) Out of hospital cardiac arrest management by first responders: retrospective review of a fire fighter first responder program. Austral J Paramed 11(5):1-7. https://doi. org/10.33151/ajp.11.5.59

Xu C et al (2020) Automated external defibrillator facility layout status and recommendations in the main urban area of Huzhou. Acad J Hum Soc Sci 3(7):97-103

Yang L, Xiong L, Yang W (2020) An accessibility spatial search algorithm to optimize defibrillator deployment in indoor space. Int J Geogr Inf Sci 35(6):1251-1272. https://doi.org/10.1080/13658816.2020. 1844890

Yonekawa C, Suzukawa M, Yamashita K, Kubota K, Yasuda Y, Kobayashi A, Matsubara H, Toyokuni Y (2014) Development of a first-responder dispatch system using a smartphone. J Telemed Telecare 20(2):75-81

Yousefi Mojir K, Pilemalm S (2013) A framework for "new actors" in emergency response systems. In: 10th international conference on information systems for crisis response and management (ISCRAM 2013), 12-15 May 2013. Baden-Baden, Germany, pp 741-746

Yousefi Mojir K, Pilemalm S (2016) Actor-centred emergency response systems: a framework for needs analysis and information systems development. Int J Emerg Manag 12(4):403-434 
Zègre-Hemsey JK, Bogle B, Cunningham CJ, Snyder K, Rosamond W (2018) Delivery of automated external defibrillators (AED) by drones: implications for emergency cardiac care. Curr Cardiovasc Risk Rep 12(11):25

Zijlstra JA, Stieglis R, Riedijk F, Smeekes M, Van der Worp WE, Koster RW (2014) Local lay rescuers with AEDs, alerted by text messages, contribute to early defibrillation in a Dutch out-of-hospital cardiac arrest dispatch system. Resuscitation 85(11):1444-1449

Zijlstra JA, Bekkers LE, Hulleman M, Beesems SG, Koster RW (2017) Automated external defibrillator and operator performance in out-of-hospital cardiac arrest. Resuscitation 118:140-146

Zijlstra JA, Koster RW, Blom MT, Lippert FK, Svensson L, Herlitz J, Kramer-Johansen J, Ringh M, Rosenqvist M, Palsgaard Møller T, Tan HL, Beesems SG, Hulleman M, Claesson A, Folke F, Olasveengen TM, Wissenberg M, Hansen CM, Viereck S, Hollenberg J (2018) Different defibrillation strategies in survivors after out-of-hospital cardiac arrest. Heart 104(23):1929-1936

Zwislewski A, Nanassy AD, Meyer LK, Scantling D, Jankowski MA, Blinstrub G, Grewal H (2019) Practice makes perfect: the impact of stop the bleed training on hemorrhage control knowledge, wound packing, and tourniquet application in the workplace. Injury 50(4):864-868

Zègre-Hemsey JK, Grewe ME, Johnson AM, Arnold E, Cunningham CJ, Bogle BM, Rosamond WD (2020) Delivery of automated external defibrillators via drones in simulated cardiac arrest: users' experiences and the human-drone interaction. Resuscitation 157:83-88. https://doi.org/10.1016/j.resuscitation. 2020.10.006

Publisher's Note Springer Nature remains neutral with regard to jurisdictional claims in published maps and institutional affiliations. 